\title{
An explanation of the occupational and educational structure of employment by means of multinomial logit
}

Citation for published version (APA):

Peeters, H. M. M. (1990). An explanation of the occupational and educational structure of employment by means of multinomial logit. Researchcentrum voor Onderwijs en Arbeidsmarkt, Faculteit der Economische Wetenschappen. ROA Working Papers No. 4E https://doi.org/10.26481/umarow.199004E

Document status and date:

Published: 01/01/1990

DOI:

10.26481/umarow.199004E

Document Version:

Publisher's PDF, also known as Version of record

Please check the document version of this publication:

- A submitted manuscript is the version of the article upon submission and before peer-review. There can be important differences between the submitted version and the official published version of record.

People interested in the research are advised to contact the author for the final version of the publication, or visit the DOI to the publisher's website.

- The final author version and the galley proof are versions of the publication after peer review.

- The final published version features the final layout of the paper including the volume, issue and page numbers.

Link to publication

\footnotetext{
General rights rights.

- You may freely distribute the URL identifying the publication in the public portal. please follow below link for the End User Agreement:

www.umlib.nl/taverne-license

Take down policy

If you believe that this document breaches copyright please contact us at:

repository@maastrichtuniversity.nl

providing details and we will investigate your claim.
}

Copyright and moral rights for the publications made accessible in the public portal are retained by the authors and/or other copyright owners and it is a condition of accessing publications that users recognise and abide by the legal requirements associated with these

- Users may download and print one copy of any publication from the public portal for the purpose of private study or research.

- You may not further distribute the material or use it for any profit-making activity or commercial gain

If the publication is distributed under the terms of Article $25 \mathrm{fa}$ of the Dutch Copyright Act, indicated by the "Taverne" license above, 
AN EXPLANATION OF THE OCCUPATIONAL AND EDUCATIONAL STRUCTURE OF EMPLOYMENT BY MEANS OF MULTINOMIAL LOGIT

ROA-W-1990/4E

H.M.M. Peeters

RESEARCH CENTRE FOR EDUCATION AND LABOUR MARKET

Faculty of Economic Sciences

Rijksuniversiteit Limburg

Maastricht, July 1990 
Peeters, H.M.M.

An explanation of the occupational and educational structure of employment by means of multinomial logit / H.M.M. Peeters. - Maastricht : Research Centre for Education and Labour Market. Faculty of Economic Sciences. Rijksuniversiteit Limburg. - (Werkdocument = Working paper / Researchcentrum voor Onderwijs en Arbeidsmarkt. ISSN 0922-4645 : 1990/4E)

Met lit. opg.

ISBN 90-5321-038-5 in ringband

SISO 318.7 UDC $331.542 / .544$

Trefw.: beroepenstructuur / opleidingsstructuur 
SUMMARY

2. OCCUPATIONAL AND EDUCATIONAL SHIFTS

3. THE MODEL 14

3.1. The economic model 14

3.2. The econometric model and estimation method 17

4. ESTIMATION RESULTS 20

4.1. The explanation of the occupational shifts within 20 branches of industry during 1979-1985

4.2. The explanation of the educational shifts within both branches of industry and occupational groups during 1979-1985 25

4.3. A comparison of the Fixed Coefficient results with the Multinomial Logit results

5. CONCLUSIONS

REFERENCES

ANNEXES

A. Branches of industry, occupational and educational groups 36

A.1. Branches of industry codes and corresponding names 36

A.2. Occupational codes and corresponding names 37

A.3. Educational codes and corresponding names 39

B. Shift and share analysis 41

B.1. Changes in the occupational structure and its components, 1979-1985

B.2. Changes in the educational structure and its components, 1979-1985 
C. Estimation of the Multinomial Logit model 45

D. The estimation results of the Multinomial Logit Method 49

D.1. The occupational model 49

D.2. The educational model 53 


\section{SUMMARY}

The fixed coefficient manpower requirements approach provides information on shifts in the occupational and educational structure of employment over time, but neglects the substitution between the various occupations and educational groups. In this study shifts in the structure of 83 occupations within 21 branches of industry in The Netherlands from 1981 to 1985 are explained by past occupational structures and technological developments. Besides, the educational structures according to 58 educational groups within the occurring combinations of the 83 occupational classes and 21 branches of industry in The Netherlands from 1981 to 1985 are explained by past educational structures, technological developments and the skill structure of labour supply. The explanation of both employment structures are carried out by means of multinomial logit. 

This study was carried out as part of a long-range research project commissioned by the Ministry of Education and Sciences. The objective of the project is to develop an education/labour-market information system to help secondary and university students choose a right type of school and/or occupation (ROA 1990).

This study reports an intermediary step towards the construction of the education/labour-market information system. Its specific purpose is to extend and improve the occupational and educational studies that already were carried out within the Research Centre for Education and Labour Market. This study can be seen as the logical continuation of these previous studies.

This study was carried out under the supervision of J.A.M. Heijke, director of the ROA, and A. de Grip. The investigation would probably have been much more cumbersome without advices of the authors of preceding studies within the ROA concerning the occupational and educational shifts. So I like to thank these authors, J.A.M. Heijke, A. de Grip, R.J.P. Dekker and Th.B.J. Beekman for their helpful advices. Beside these persons thanks are due to $L$. Borghans who also contributed much to this study. 



\section{INTRODUCTION}

In the course of years the composition of employment has ever been changing. Looking at the composition of occupations the arising of new occupations, the vanishing of old trades and shifts of employment between occupations can be observed. These occupational shifts are determined by the changing demand of employers due to product market, technological and organizational developments, and other underlying processes. Beside and possibly partly because of these shifts the educational structure of employment has also undergone noticeable changes.

Both the occupational and educational structure of employment have been studied extensively. Many empirical studies have been carried out by considering the occupations or the highest educational level reached of the employed population within branches of industry. Singelmann and Browning (1980) used a "shift and share" method to analyze the occupational structure of several branches of industry in the U.S. from 1960 until 1970. This method resembles the "fixed coefficient" method, which assumes that shares of numbers of employed persons within industries are constant in time so that substitution between occupations (or educations) is impossible. This fixed coefficient method is compared by Freeman (1980) with a method that takes into account the changing accompanying wage structure of occupations. Freeman (1986) thereby examines among others the fixed coefficient method applied to the educational structure within industries. The results of these studies do not reject this relatively conservative method.

On the one hand the purpose of this study is to explain the occupational structure within branches of industry and on the other hand to explain the educational structure within both occupations and branches of industry in The Netherlands. Both problems have already been examined within the Research Center for Education and Labour Market (Dekker et al. (1988) and Beekman et al. (1989)). The difference between this study and the two studies mentioned above concerns mainly the estimation method used; here the Multinomial Logit method is used whereas in the two previous studies the models were estimated by Weighted Least Squares. Moreover the explanatory models here take into account the rigidity of the occupational and educational structure by relating the present structures to past structures. 
Other Dutch studies of occupational and educational shifts within industries during last decades are found among others in Bekkering et al. (1988) and Van Opstal (1988) respectively. Contrarily to Van Opstal and Bekkering here a large number of occupations and educations are distinguished. We distinguish 83 occupations and 58 educations whereas Bekkering takes into account (mostly) 14 occupational groups and Van Opstal 14 educational groups. The reason for analyzing the occupational and educational structures at such a disaggregated level originates from the research project of the Research Centre for Education and Employment aiming at the creation of an information system on education and labour market that among others has to be suitable for educational and vocational counseling purposes. Medium term labour market forecasts for occupational and educational groups are an important part of this information system; at this moment the information system explores a model to forecast at medium term the working population within 21 branches of industry, 83 occupations and 58 educations. Because the Dutch Central Planning Bureau provides the industrial forecasts, here the occupational and educational parts have only to be considered.

Chapter 2 contains a short description of the available data set and analyzes the occupational and educational structures by means of a shift and share method. As the results of this analysis indicate that the fixed coefficient method traditionally used in manpower requirements analysis does not fully explain occupational and educational shifts, an explanatory model for these shifts is introduced in chapter 3. The explanatory variables and estimation method used are considered only shortly; most explanatory variables were already introduced by Dekker et al. and Beekman et al. and the estimation method, Multinomial Logit, resembles the estimation method introduced by Parks (1980). Chapter 4 presents the estimation results. Finally chapter 5 summarizes the main results and concludes.

Concerning the analyses one remark has to be made. The main purpose of this study is the application of the estimation method, Multinomial Logit, to the occupational and the educational model. The occupational model explains the 83 occupational shares of employed persons within 21 branches of industry whereas the educational model explains the 58 educational shares of employed persons within combinations of branches of industry and occupations. Because of the difficulty to present all results in a surveyable way we introduce two models at a higher level of aggregation that resemble the two models mentioned; in these models only 7 occupational groups and 5 educational 
$-3-$

levels are distinguished. It should be clear that these models are only presented for illustrative reasons. 

2. OCCUPATIONAL AND EDUCATIONAL SHIFTS

\subsection{The data}

Like all Dutch studies mentioned in the introduction, we also used the Dutch Labour-Force Censuses (from the Dutch Central Bureau of Statistics) for our analyses. In this chapter the results of a shift and share analysis applied to these data are shortly discussed. In advance the way these data were organized for explaining the occupational and educational shifts is scrutinized.

The Dutch Labour-Force Censuses are sample survey's ranging from $2.5 \%$ to $5.0 \%$ of the total labour force and were held every two year from 1975 until 1985. From persons surveyed the occupational group, the branch of industry and the highest educational qualification reached are of importance for our study. Because the samples of 1975 and 1977 use other educational classifications these years are not taken into account, so only four years are left. In this study the highly disaggregated industries, occupations and educations within the Labour-Force Censuses are aggregated in such a way that a reasonable number of well defined industries, occupations and educations remain 1 . In annexes A.1. until A.3. the final division in 21 branches of industry, 83 occupations and 58 educations and their so called 2-digit codes are given. For convenience's sake the 83 occupations and 58 educations are also aggregated to seven main occupational categories (corresponding to the 1-digit occupations) and the five Dutch educational levels.

Table 1. Occupational categories (1-digit)

\begin{tabular}{llc}
\hline Category & Description of occupations & 1-Digit ISCO \\
\hline 1 & & 0,1 \\
2 & Professional, technical and related workers & 2 \\
3 & Administrative and managerial workers & 3 \\
4 & Clerical and related workers & 4 \\
5 & Sales workers & 5 \\
6 & Service workers & 6 \\
7 & Agricultural workers, fishermen & $7,8,9$
\end{tabular}

1. The disaggregated occupations and educations are comparable with 2 digit ISCO and 3 digit ISCED level respectively. 
Table 2. Educational levels

Category Educational level

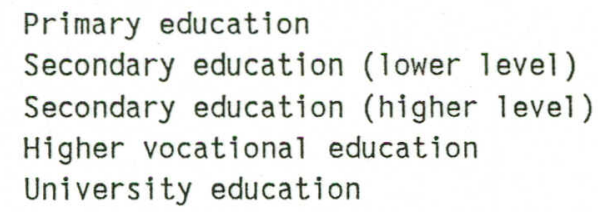

These categories of occupations and educations are mentioned in table 1 and 2 respectively. Employment shifts between these occupational categories from 1979 unti1 1985 are shown in figure I, where the seven numbers at the $x$-axis correspond to the seven categories mentioned in table 1. Obviously the monotonously increasing employment of the professional, technical and related workers (category 1 ) and the decline of the production and related workers (category 7) catch the eye.

Figure I. Working population within seven occupational categories during 1979-1985

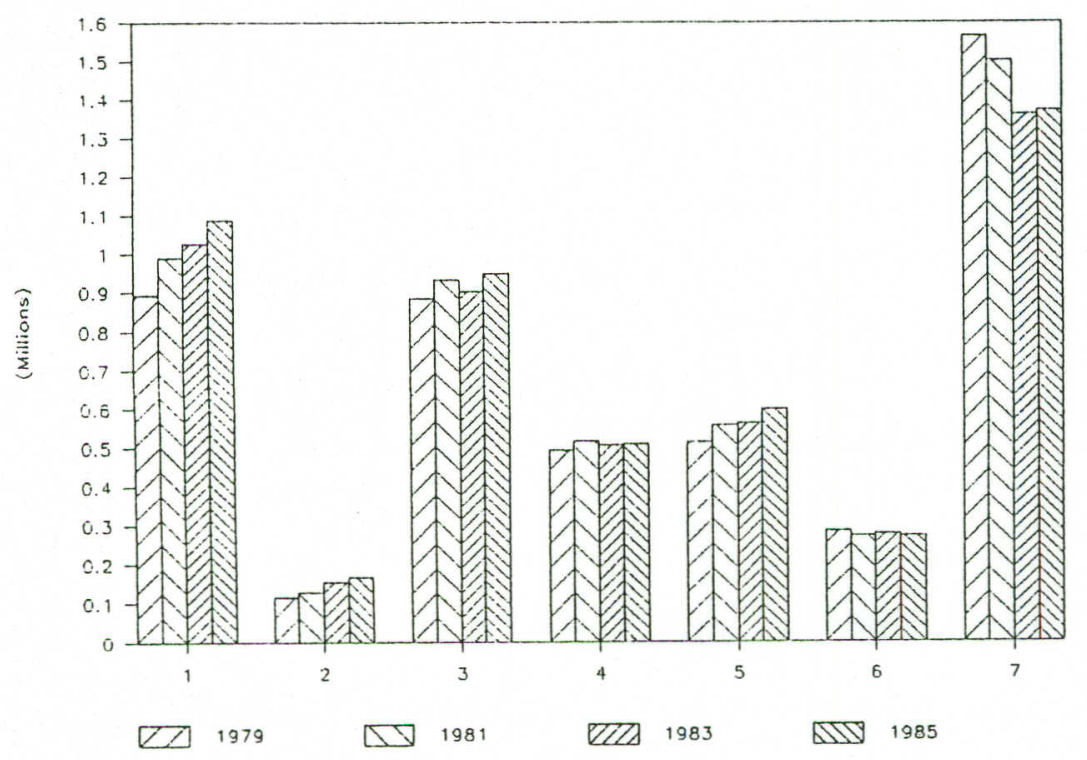

The figures IIa and IIb illustrate the educational background of the employed population in these seven categories in 1979 and 1985 . Because the seven categories are ranked from the highest to the lowest level occupations, it is not surprising that occupational category 1 contains relatively less persons with the lowest and more persons with the highest 
educational level than the other categories. Nevertheless, much more important here are the shifts in almost all occupations from the lower to the higher educational levels during 1979-1985.

Figure IIa. Educational background of persons employed within seven occupational categories in 1979

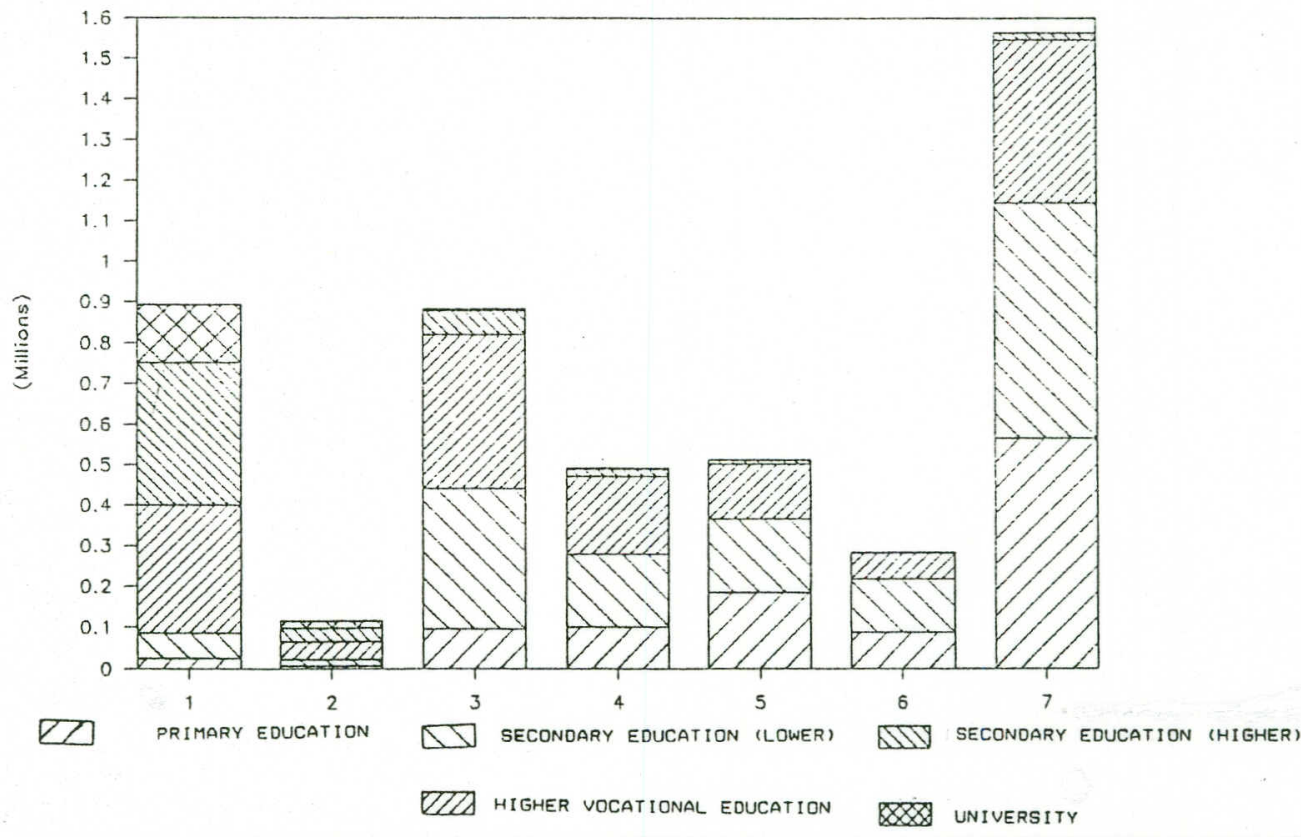

Figure IIb. Educational background of persons employed within seven occupational categories in 1985

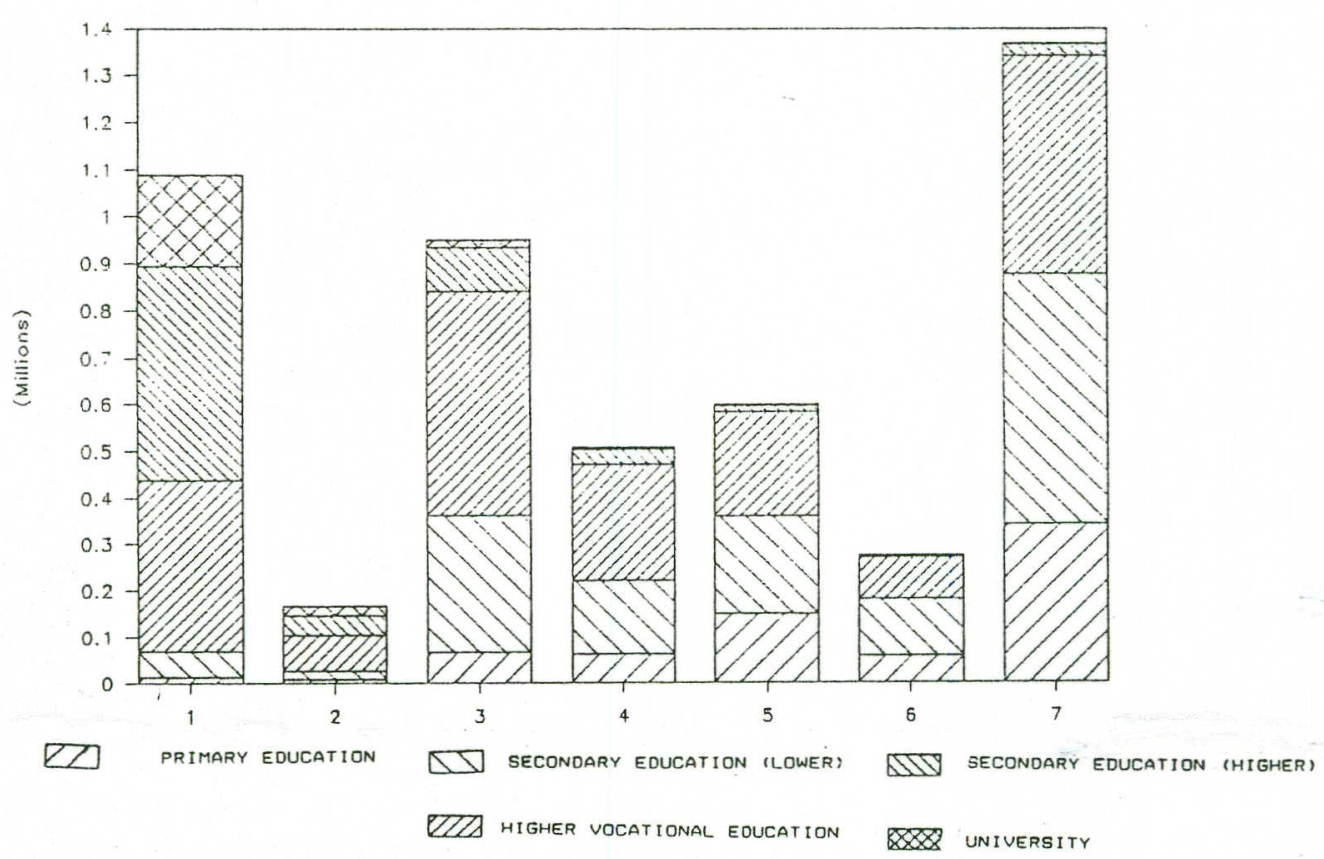


The figures IIa and IIb show the changing occupational and educational structure of employment but do not show us the way industries have expanded or shrunk. It could be possible that the changing occupational and educational structure is mainly caused by a changing industrial structure. In the next section attention is paid to shifts in the industrial structure and the occupational and educational structure within branches of industry.

Moreover looking at numbers of persons employed, like is done above, it seems also necessary to take into account the reduction of working hours that took place during 1979-1985. The reason for an increase in the number of persons employed in a certain industry and therefore an increase in the occupations that are represented in this industry could probably be traced back to the reduction of working hours. For this reason we used the results of a study in which the average working time of occupations within industries was estimated by making use of data about the average working time of the working population in occupations and data about the working time of the working population in branches of industry. The estimation was carried out by a so called RAS-procedure (Groot and Heijke, 1989). The number of hours worked are sorted in eight categories and the number of persons within these eight categories are estimated for every occupation within a branch of industry. We define:

\footnotetext{
$E P(b, o, t) \quad$ : employed persons in branch of industry $b$, occupation o at time $t$ (directly from the Labour-Force Censuses);

$\operatorname{EP}^{*}(b, o, h, t)$ : number of employed persons in branch of industry $b$, occupation $o$, class of working hours $h$ at time $t$, estimated by the RAS-procedure;

$\mathrm{MH}(\mathrm{h}) \quad$ : average number of hours of the class of hours $h$.
}

The variable $h$ indicates the eight categories of working hours distinguished (so $h=1,2 \ldots 8$ ), where each category represents a class of working hours (e.g. category 1 is the working hours category that ranges from 0 working hours to 16 working hours, etc.). We calculated the number of employed persons adjusted for the share of part-time work, which gives us employment in person-years, defined as AEP, by transforming the employed persons of the Labour-Force Censuses:

$$
A E P(b, o, t):=\frac{\sum_{h} E P^{*}(b, o, h, t) * M H(h)}{\sum_{h} E P^{*}(b, o, h, t) * 40} * E P(b, o, t)
$$


The first term right of the equality symbol represents the average number of working hours of occupation 0 within industry $b$. The denominator of this term contains the normal working time of occupation 0 and industry $b$, which is here assumed to be 40 hours a week. By multiplying the first term by the number of persons employed in occupation 0 and industry $b$, which is the second term, the adjusted number of employed persons is found.

One conclusion of the study of Groot and Heijke mentioned above is that the shares of part-time work as measured by average working time per week are more determined by occupation than by industry. In figure II I the employed persons and adjusted number of employed persons within the seven main occupations in 1979 and 1985 are compared. The correction for working hours is bigger in 1985 than in 1979 and seems to have the least impact on administrative, managerial workers and agricultural occupations (category 2 and 6 ). The relative small difference between adjusted and unadjusted numbers of employed persons in the agricultural industry is also found in figure IV; for the three main branches of industry the agricultural industry shows the least differences by the adjustments made.

Figure III. Employed persons and employed persons adjusted for the share of part-time work within seven occupational categories in 1979 and 1985

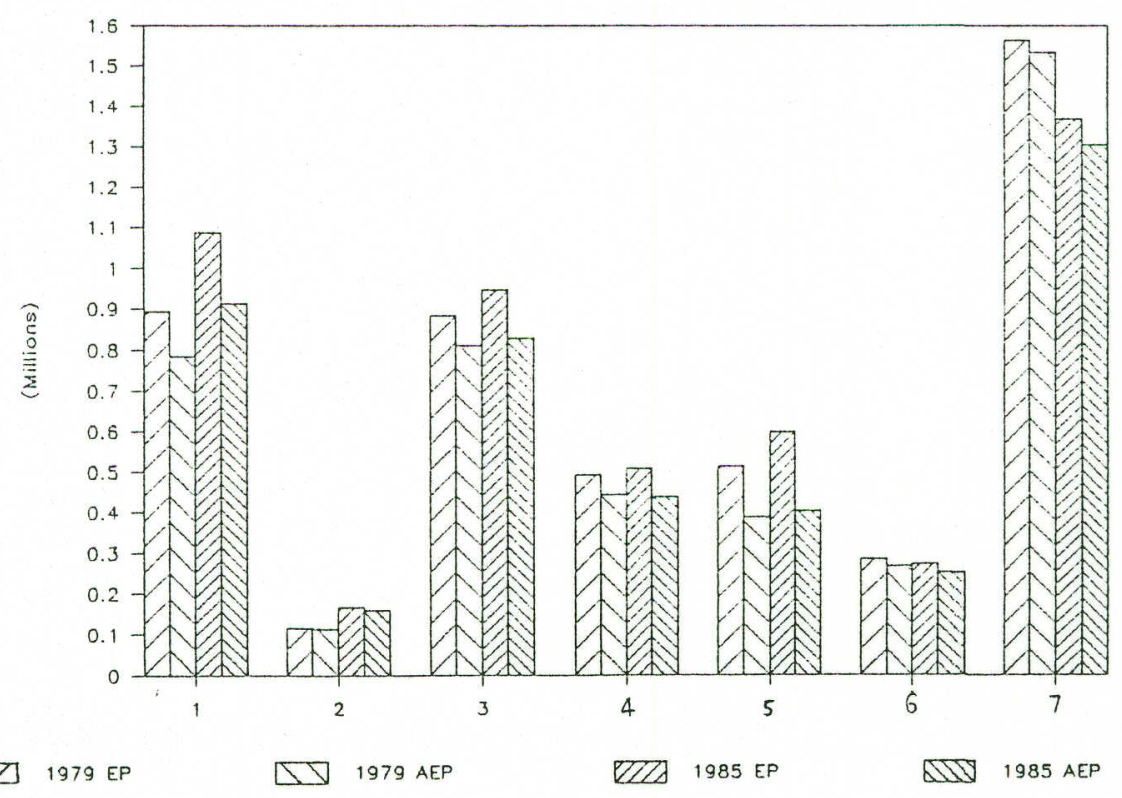


Figure IV. Employed persons and employed persons adjusted for the share of part-time work within three branches of industry in 1979 and 1985

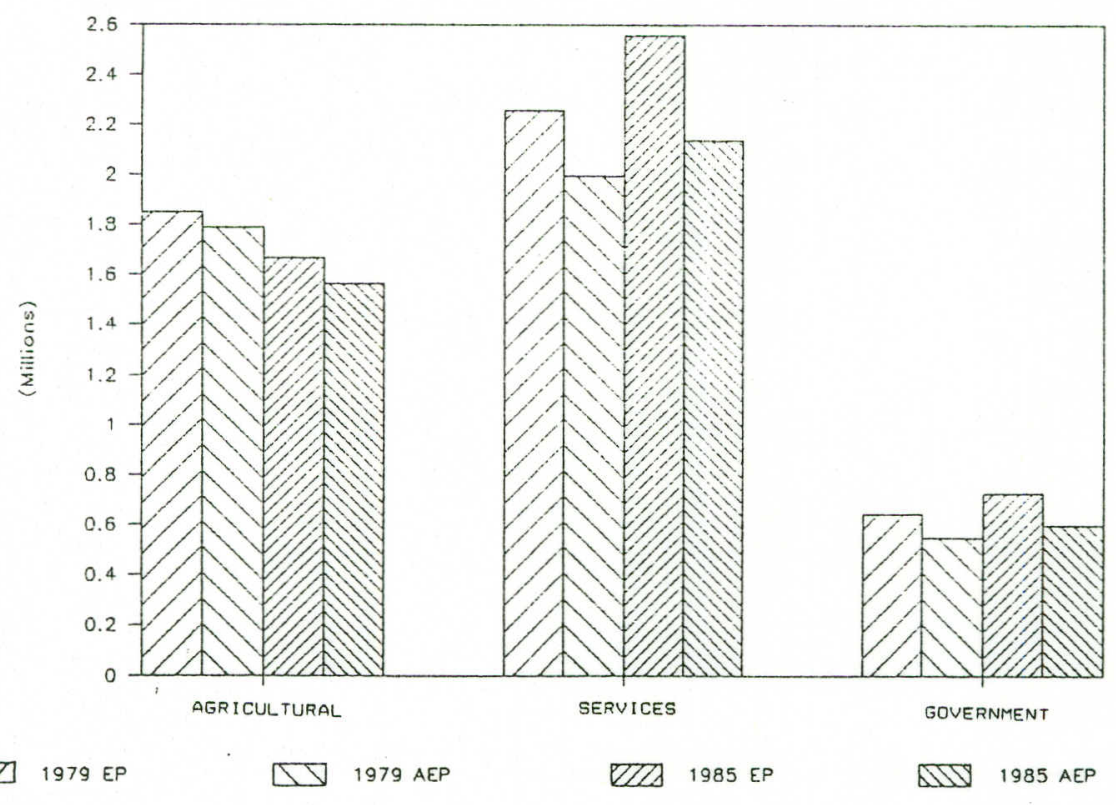

We assume that the adjustments for working hours of the number of employed persons with a certain educational background is fully determined by the occupation within a branch of industry they have. We therefore calculate the adjusted number of employed persons with certain educational backgrounds by multiplying those numbers with the average number of working hours of the occupation they have and industry they were working, $\mathrm{so}^{2}$

$$
\operatorname{AEP}(b, 0, e, t):=\frac{\sum_{h} E P^{*}(b, o, h, t) * M H(h)}{\sum_{h} E P^{*}(b, o, h, t) * 40} * E P(b, o, e, t)
$$

with

$\mathrm{EP}(b, \mathrm{o}, \mathrm{e}, \mathrm{t})$ : number of employed persons within industry $b$, occupation $o$, education $e$ at time $t$;

$\operatorname{AEP}(b, o, e, t)$ : adjusted number of employed persons within industry $b$, with occupation 0 and education e at time $t$.

2. For the estimation method we use in chapter 3 there is no difference between taking account of the employed people or the adjusted employed people when calculating the endogenous variable of the educational model. This is because of the fact that nominator and denominator are adjusted by the same factor. Only the estimated covariance matrix is touched by the adjustments made here for part-time work. 


\subsection{Shift and share analyses}

Every branch of industry has its own occupational and educational structure. In some branches certain occupations will be well represented. The agricultural industry for example obviously possesses most of the agricultural occupations. So a relative decrease of employment in the agricultural industry structure will automatically cause a relative decrease in the agricultural occupations. This effect is called the industry structure effect. Given this industry structure the occupational structure within branches of industry can also change, for example if the computerization of industries implies increasing demand of automation experts substituting clerical occupations. This effect is called the occupational structure effect. Finally, it is possible that within certain occupations the educational level increases due to the abundant supply of higher educated persons. This shift effect is called the educational structure effect. We here analyze these three effects for the seven occupations and five educational levels mentioned in section 2.1. Besides the three structure effects we distinguish an interaction effect ${ }^{3}$.

Table 3 shows the results of this shift and share analysis for the occupational structure of the seven occupations within the 21 distinguished industries. All numbers of persons are adjusted for restrictions in working hours $(\operatorname{see}(1))^{4}$.

From 1979 until 1985 an occupational shift took place towards the "professional", "administrative", "clerical" and "service" occupations at the expense of the "agricultural" and "industry" occupations (see column "Net shift"). The decline of the agricultural and production occupations is mainly, by $83 \%$ and $70 \%$ respectively, due to industry shifts but is also caused by the occupational shift within these industries (column "Occupational shift effect").

3. Other labour market studies using shift-share analyses are e.g. Singelmann and Browning (1980), NEI (1986), Grip (1987) and Teulings (1990).

4. For a complete description of the shift and share analysis used, see annex B.1. 
Table 3. Changes in the occupational structure and its components, 1979-1985

\begin{tabular}{|c|c|c|c|c|c|c|c|}
\hline & \multicolumn{4}{|c|}{ Components of net shift } & \multicolumn{3}{|c|}{$\begin{array}{l}\text { Components of net shift } \\
\text { (percentages) }\end{array}$} \\
\hline & $\begin{array}{l}\text { Net } \\
\text { shift }\end{array}$ & $\begin{array}{l}\text { Industry } \\
\text { shift } \\
\text { effect }\end{array}$ & $\begin{array}{l}\text { Occupation } \\
\text { shift } \\
\text { effect }\end{array}$ & $\begin{array}{l}\text { Interaction } \\
\text { effect }\end{array}$ & $\begin{array}{l}\text { Industry } \\
\text { shift } \\
\text { effect }\end{array}$ & $\begin{array}{l}\text { Occupation } \\
\text { shift } \\
\text { effect }\end{array}$ & $\begin{array}{l}\text { Inter. } \\
\text { effect }\end{array}$ \\
\hline Profess. & 138237 & 98379 & 40676 & -818 & 71.2 & 29.4 & -0.6 \\
\hline Administ. & 46867 & -815 & 53341 & -5659 & -1.7 & 113.8 & -12.1 \\
\hline Clerical & 24045 & 22148 & 520 & 1377 & 92.1 & 2.2 & 5.7 \\
\hline Sales & -937 & -11012 & 11815 & -1740 & 1175.2 & -1260.9 & 185.7 \\
\hline Services & 19748 & 51732 & -28583 & -3401 & 262.0 & -144.7 & -17.2 \\
\hline Agricult. & -14466 & -11952 & -3130 & 616 & 82.6 & 21.6 & -4.3 \\
\hline Product. & -213495 & -148482 & -74640 & 9627 & 69.6 & 35.0 & -4.5 \\
\hline
\end{tabular}

Explanation column titles :
Net shift : Change in occupational structure because of industry and occupational shifts;
Industry shift effect : Change in occupational structure because of industry changes;
Occupational shift effect : Change in occupational structure because of occupational structure changes within industries;
Interaction shift effect : Changes in occupational structure as a consequence of changes in both occupational and industrial shifts that are not directly attributable to one of both effects.

Except the "administrative" occupations, all other occupational category shifts are for at least $70 \%$ due to industrial shifts. The interaction effects with these occupations are negligible, which implies that occupational and industrial effects by themselves have large effects on changes in the occupational structure. The occupational category "administrative" has obviously gained most by the changing occupational structure within industries. In view of the total expansion the negative interaction effect did not play a big role.

Table 4 contains the results of the shift and share analysis of the educational shifts within industries and occupations. The first column contains the educational shifts within industry-occupation-combinations. Comparing the educational structure of 1979 and 1985, we see that the shift towards the higher level educations is mainly due to the changing structure of educations within industries and occupations. Interaction effects are hardly noticeable. The results of a shift and share analysis applied to the educational structure within occupations (so neglecting the industrial structure) and the results of a shift and share analysis applied to the 
educational structure within industries (so neglecting the occupational structure) do not differ much from these results. The differences that are found (especially at the extended primary and secondary education) are possibly ascribable to changing occupations within industries that were mainly held by persons with these educations.

Table 4. Changes in educational structure and its components, 1979-1985

Components of net shift shift

Primary

Secon. lower

Secon. higher

Higher

University

-366346
-145690
318632
138283
55121

$-74007$

$-60057$

37338

66425

30098
Components of net shift

(percentages)

The results above are not remarkable. It is obvious that the occupational structure is much more influenced by industry shifts than the educational structure, which is probably much more effected by the labour supply and the degree of scarcity on the labour market.

For the sake of completeness these shift and share analyses were also applied to the 83 occupations and 58 educations (1isted in annex A2 and A3). The results are in annexes B.1 and B.2. These shift and share analyses at a lower level of aggregation lead largely to the same conclusions as the analysis at the higher level of aggregation, so the occupational and educational shifts are more due to industrial shifts and shifts of the educational structure within industries and occupations respectively.

In annex B.1 however the divergence of the explanation of the changing occupational structure within an occupational category immediately catches the eye. For example the four most changing occupations in the occupational category "professional" are explained by different effects; the employed persons in occupation 5, "medical", occupation 10 "teachers" and occupation 16 "professional, technical" expanded as a consequence of industrial shifts, whereas occupation 6 "statisticians" increased as a result of occupational 
shifts within industries. The same can be observed within the service workers category (category 5). In addition the figures show that the occupational category "production" (category 7) for almost all thirty occupations that are distinguished had a very bad time during 1979-1985.

Annex B.4 shows big changes within the "technical", "social" and "economicclerical" educations at nearly all levels. The technical educations at the extended primary and secondary levels (education 4 and 14) declined considerable, whereas these educations at the higher levels (education 30-31 and 48-49) expanded strongly. These shifts were not mainly caused by an industrial or educational effect within industry-occupation-combinations. The "social" educations at the higher levels (education 39 and 55) and the "economic-administrative" educations (education 19, 36-37, 52-53) owe their growth to educational changes.

From these results might be concluded that it does not seem acceptable to neglect changes in industrial, occupational and educational structures. The most relevant result for us is however the fact that the assumption of a constant occupational and educational structure within industries and industry-occupation-combinations respectively is objectionable (columns "industry shift effect" and "ind.-oc. shift effect" in table 3 and table 4 respectively); so it seems important to find explanations for the changing occupational and educational structures.

In the next section we describe a method to explain the occupational and educational structure within industries and industry-occupationcombinations. This method should improve the forecasts of the occupational and educational shifts during 1979-1985 compared to the constant shift methods. 
3. THE MODEL

\subsection{The economic model}

In this chapter the economic models of both the explanation of the occupational and educational shifts are described. Further a formal description of both models and the estimation method used is shortly discussed.

The manpower requirements models relate employment of a certain occupation or education to industrial employment. In the fixed manpower requirements model these shares are assumed to be constant in time, so that substitution among different types of labour is not possible. This method was also used in chapter 2 (table 3 and 4, column 2). In the study of Freeman (1980) the fixed manpower requirements model for different types of occupations during 1960-1970 are discussed, while the study of Freeman (1986) discusses the model for different types of education. Because this model neglects the possibility of substitution between types of labour, Freeman also uses different explanatory models. In Freeman (1980) the wage structure corresponding to the occupations is taken into account and as a result the fixed coefficient model is not rejected because of the relative moderate variation of the wage structure. In Freeman (1986) it is emphasized that the fixed method can play an important role even if the negligence of substitution possibilities seems not realistic.

Like Dekker et al. (1988), Beekman et al. (1989) and Van Opstal (1988) we want to explain the manpower coefficients by assuming a relationship between these coefficients and some relevant economic variables. Van Opstal uses as dependent variable in his econometric modeling the employment of educational categories within industrial employment and thereby skips the occupational level of analysis. Contrarily, we first relate employment of an occupational category to industrial employment and then relate the employment of an educational category to the employment of a industryoccupation-combination. We define:

$\operatorname{AEP}(0, e, t)$ : number of employed persons with occupation 0 , education e at time $t$;

$\operatorname{AEP}(b, t) \quad$ : number of employed persons within industry $b$ at time $t$;

$p_{t}(e \mid b, 0)$ : fraction of employed persons with education e within industry $b$, occupation $o$ at time $t$;

$p_{t}(0 \mid b) \quad$ : fraction of employed persons with occupation $o$ within industry $b$ at time $t$. 
Then the following identity holds:

$\operatorname{AEP}(0, e, t)=\Sigma_{b} p_{t}(0 \mid b) p_{t}(e \mid b, 0) \operatorname{AEP}(b, t)$

The fixed manpower requirements model assumes $p_{t}(o \mid b)$ and $p_{t}(e \mid b, t)$ to be independent of time. Here we assume these coefficients to depend on economic factors. We distinguish the occupational fraction from the educational fraction, thereby assuming that the occupational and industrial structure represent the demand side of the labour market whereas the educational structure of industries and occupations is a result of the matching process of labour supply and labour demand (see De Grip et al., 1989).

The variables used for explaining the fractions of occupations are defined as:

$\mathrm{p}_{\mathrm{t}-2}(\mathrm{o} \mid \mathrm{b})$ : the fraction of occupation 0 within industry $\mathrm{b}$ at time $\mathrm{t}-2$;

INVVA $(b, t)$ : the investments related to value added in industry $b$ at time $t$;

$\operatorname{DCU}(b, t) \quad$ : the degree of capacity utilization of industry $b$ at time $t$.

The variables used for explaining the fractions of educations are defined as:

$\mathrm{p}_{\mathrm{t}-2}(\mathrm{e} \mid \mathrm{b}, \mathrm{o})$ : the fraction of education e within industry $\mathrm{b}$ and occupation $\mathrm{o}$ at time $\mathrm{t}$;

$\operatorname{INVVA}(b, t)$ : see above;

$\operatorname{DCU}(b, t) \quad$ : see above;

$\operatorname{PLF}(e, t)$ : potential labour force of education e at time $t$.

As the dependence of the current occupational and educational structures from the past structures should not be neglected, this dependence is taken into account. Resulting from the fact that we work with bi-annual data, the fractions of two years ago are considered. By taking account of these past fractions the other variables in the model should explain the shifts per occupation and education from time $t-2$ to $t$.

Above mentioned parts of both models are firstly explained by a variable representing technological progress per industry (variable INVVA(b,t)). This 
variable is measured as ${ }^{5}$ :

$$
\operatorname{INVVA}(b, t):=\left[\sum_{j=-9}^{0} \operatorname{INV}(b, t+j)\right] /\left[\sum_{j=-9}^{0} \operatorname{VA}(b, t+j)\right]
$$

where

$\operatorname{INV}(b, t):$ investments in industry $b$ at time $t$;

$\mathrm{VA}(\mathrm{b}, \mathrm{t})$ : value added in industry $\mathrm{b}$ at time $\mathrm{t}$.

The second variable used for explaining the shifts per occupation and education during time t-2 until $t$ is the degree of capacity utilization that represents cyclical effects in the employment structure. This variable is constructed as

$$
\operatorname{DCU}(b, t)=: \operatorname{VA}(b, t) /\left[1 / 5 \sum_{j=-2}^{2} V A(b, t+j)\right]
$$

It is assumed that the changing investments and degrees of capacity utilization both influence the occupational and educational structure and that this influence is different between occupations and educations. It seems reasonable to assume that some occupations or educations take advantage of the changing technological developments at the expense of other occupations or educations. If lower skilled persons are substituted by higher skilled persons one is speaking of upgrading, the opposite case is downgrading. Developments like upgrading or downgrading might in this way be examined. The two variables mentioned are both industrial-specific, so might be seen as determined by the demand side of the labour market.

By explaining the educational fractions the supply side of the labour market is taken into account by means of the variable PLF. The supply of persons with certain educational qualifications may cause shifts within the educational structure. From the data we used it was after all obvious that during 1979-1985 a considerable expansion of higher educated employed persons took place which could be a reflection of the high growth rate of

5. This variable slightly differs from the variable used in Dekker et al. (1988) and Beekman et al. (1989) as we here specified the variable over a period of 10 in stead of 5 years, taking account of longer diffusion lags of technical progress. 
relative labour supply of higher educated persons 6 .

Summarizing, the fractions of occupations within industries and the fractions of educations within branch-occupation-combinations are here assumed to depend on the one hand on demand side industrial-, occupationaland on the other hand on educational-specific supply-side variables.

\subsection{The econometric model and estimation method}

In equation (3) the occupational and educational fractions are found. The occupational fractions are assumed to be a transformation ( $f_{0}$ ) of the past fraction and industrial variables $\left(x_{b t}\right), s^{7}$

$$
p_{t}(0 \mid b)=f_{0}\left(p_{t-2}(o \mid b), x_{b t}\right)
$$

The educational fractions are assumed to be a transformation $\left(f_{e}\right)$ of the past fraction, the educational (xet) and industrial variables, so

$$
p_{t}(e \mid b, 0)=f_{e}\left(p_{t-2}(e \mid b, 0), x_{b t}, x_{e t}\right)
$$

Because these relations are assumed to be the same, we define

$$
p_{t}(i \mid g)=f_{i}\left(p_{t-2}(i \mid g), x_{i t}, x_{g t}\right)
$$

where $i$ and $g$ represent occupation 0 and branch $b(i=0$ and $g=b)$ or education $e$ and the combination of branch $b$ and occupation $o(i=e$ and $g=(b, 0))$. We will use this equation while considering the estimation method, and refer to $\mathrm{i}$ and $\mathrm{g}$ as the category of labour and the branch respectively.

The estimation method used is the multinomial logit method. This method assumes the fraction of a category of labour $i$ within a branch to be logistically distributed, which means that the function $f_{j}$ in (8) is the logistical density function. The probability that category $i$ occurs within branch $\mathrm{g}$ is therefore assumed to be :

6. The variables INVVA, DCU and PLF were also used in Dekker (1988) and Beekman (1989).

7. For convenience's sake we assume here that there is only one industrialspecific variable. 


$$
p_{t}(i \mid g)=\frac{\exp \left[\alpha \ln \left(p_{t-2}(i \mid g)\right)+x_{g t}{ }^{\top} \beta_{i}+x_{i t}{ }^{\top} \tau_{j}+e_{i g t}\right]}{\sum_{k} \exp \left[\alpha \ln \left(p_{t-2}(k \mid g)\right)+x_{g t}{ }^{\top} \beta_{k}+x_{k t}{ }^{\top} \tau_{k}+e_{k g t}\right]}
$$

Because equation (9) does neither consider the employment distribution within branches nor individual jobs with individual characteristics, the equation only represents average variables. The term $e_{i g t}$ is therefore added to the specification as a specification error. The parameters $\alpha, \beta_{j}$ and $\tau_{j}$ are the parameters of interest that are to be estimated. The parameters $\beta_{j}$ and $\tau_{j}$ represent the individual influence of the variables $x_{g}$ and $x_{j} t$ on the labour category $i$.

By choosing a reference group of labour, say labour $i^{*}$, dividing by $p_{t}\left(i^{*} \mid g\right)$ and taking natural logarithms, equation (9) gives

$$
\begin{aligned}
\ln \left(p_{t}(i \mid g) / p_{t}\left(i^{*} \mid g\right)\right)= & \alpha \ln \left(p_{t-2}(i \mid g) / p_{t-2}\left(i^{*} \mid g\right)\right)+x_{g t}{ }^{\top}\left(\beta_{i}-\beta_{i}{ }^{*}\right)+ \\
& x_{i t}{ }^{\top} \tau_{i}-x_{i}{ }^{*} t^{\top} \tau_{i}{ }^{*}+e_{i g t}-e_{i}{ }^{*} g t
\end{aligned}
$$

Because of this resulting equation the lagged variable is logarithmically specified in equation (9). When estimating equation (10) there is one parameter estimation for $\beta_{j}-\beta_{j}$. That is why mostly $\beta_{j}$ * is assumed to be zero.

Instead of the theoretical probabilities $p_{t}(i \mid g)$ the frequencies $f_{t}(i \mid g)$ are observed, so equation (10) might be rewritten as

$$
\begin{aligned}
\ln \left(f_{t}(i \mid g) / f_{t}\left(i^{*} \mid g\right)\right)= & a \ln \left(f_{t-2}(i \mid g) / f_{t-2}\left(i^{*} \mid g\right)\right)+x_{g t}{ }^{\top} \beta_{i}+ \\
& x_{i t}{ }^{\top} \tau_{j}-x_{i}{ }^{*} t^{\top} \tau_{j}{ }^{*}+e_{i g t}-e_{i}{ }^{*} g t+w_{i g t}
\end{aligned}
$$

where

$$
w_{i g t}=\ln \left(f_{t}(i \mid g) / f_{t}\left(i^{*} \mid g\right)\right)-\ln \left(p_{t}(i \mid g) / p_{t}\left(i^{*} \mid g\right)\right) .
$$

The total disturbance consists of two errors, namely the specification error $e_{i g t}-e_{j}{ }^{*} g t$ and the measurement error $w_{i g t}$.

Equation (11) can be estimated by Modified Multinomial Logit (MML). This 
method takes into account both the specification and measurement error. In fact this method boils down to executing the Generalized Least Squares method twice. First the measurement error is taken into account (called Standard Multinomial Logit $=S M L$ ) and in a second stage the specification error is taken into account (MML) by making use of the results of the first estimation. The MML-method was introduced for the multinomial case by Parks (1980). The estimation method was used for the estimation of the manpower coefficients by Van Opstal (1988). We used this method for the estimation of our models that will be considered in the next section. There are however some differences between our models and the model of Van Opstal. These differences are due to the fact that we made use of highly disaggregated occupational and educational categories (namely 83 occupations and 58 educations). Because not all occupations distinguished occurred during 19791985 within all 21 branches and of course not all educations occurred within all occurring branch-occupation-combinations (and some of them still do not exist), we encountered problems when estimating the models by Modified Multinomial Logit. In the next section we therefore present first the results of the models at a more aggregated level (7 occupational categories and 5 educational levels). These models are estimated by both the SML- and the MML-method. The models with the highly disaggregated occupations and educations are estimated by the SML-method and next by a method that differs in some aspects from the MML-method but still takes account of the specification error. The ins and outs of the problems we encountered and the estimation procedure of the MML-method are discussed in more detail in annex C. 


\section{ESTIMATION RESULTS}

\subsection{The explanation of the occupational shifts within branches of industry during 1979-1985}

The results of the occupational and educational models that explain the share of 83 occupations and 58 educations respectively are presented in annex $D$. The much smaller problems in which only seven occupations with five educational levels distinguished are fully presented in this chapter. All estimation results coupled with the problems encountered during the estimation procedures are discussed here.

For being complete we recall the econometric model of the occupational structure within branches of industry that was introduced in the preceding chapter (see also annex C) :

$$
\begin{aligned}
\ln \left(f_{t}(0 \mid b) / f_{t}\left(0^{*} \mid b\right)\right)= & a \ln \left(f_{t-2}(0 \mid b) / f_{t-2}\left(0^{*} \mid b\right)\right)+\sum_{i=1}^{0} \beta_{1 i} \operatorname{INVVA}(b, t)+ \\
& \sum_{i=1}^{0} \beta_{2 i} \operatorname{DCU}(b, t)+\delta_{o b t}
\end{aligned}
$$

$f_{t}(0 \mid b) \quad$ : fraction of employed persons observed with occupation 0 within industry $b$ at time t;

INVVA $(b, t) \quad:$ the investments related to value added in industry $b$ at time $t$;

$\operatorname{DCU}(b, t) \quad$ : the degree of capacity utilization of industry $b$ at time $t$;

$\delta_{\mathrm{obt}} \quad:$ error term containing both the measurement and specification error;

$\alpha, \beta_{1 j}, \beta_{2 j} \quad$ : parameters to be estimated;

: occupation $(0=1,2 \ldots 0)$;

$0^{*} \quad$ : reference occupation;

b : branch of industry $(b=1,2 \ldots 21)$;

t $\quad$ : time index $(t=1981,1983,1985)$.

If only seven occupations are distinguished (see table 1 ), the index variable o ranges from 1 to 7 . A problem encountered when estimating this model concerns the lagged endogenous variable. As not every occupational group is represented within every branch of industry, fewer than the maximum number of observations (21 industries times 7 occupations times 3 years) are observed and thus explained. The non-existence of an occupational group during the sample period causes zero observations of the lagged endogenous variable which is impossible because of the in-transformation. We solved this problem by substituting the zero observations of the lagged variable by a dummy value of one employed person, so assuming one employed person 
working within this (within that year not occurring) occupation. This is of course an artificial solution but does not seem to contribute much to the estimation results because only a few times an observation of the lagged variable is missing. This solution to the missing past observations is followed in both the occupational and educational model 8 .

Table 5. Estimation results of the occupational model (7 occupations)

STANDARD MULTINOMIAL LOGIT

\begin{tabular}{lcr} 
& \multicolumn{1}{r}{ B } & SD \\
LEND0 & 0.9858 & 0.0004 \\
INVVA1 & 0.0163 & 0.0075 \\
INVVA2 & -0.235 & 0.0174 \\
INVVA4 & 0.4097 & 0.0263 \\
INVVA5 & 0.2019 & 0.0101 \\
INVVA6 & 0.6653 & 0.0493 \\
INVVA7 & 0.1412 & 0.0082 \\
DCU1 & 0.0171 & 0.0015 \\
DCU2 & 0.1245 & 0.0025 \\
DCU4 & -0.0135 & 0.0023 \\
DCU5 & -0.0455 & 0.0016 \\
DCU6 & -0.0939 & 0.0056 \\
DCU7 & -0.0366 & 0.0015
\end{tabular}

MODIFIED MULTINOMIAL LOGIT

$\begin{array}{lrr} & \text { B } & \text { SD } \\ \text { LEND0 } & 0.9745 & 0.0089 \\ \text { INVVA1 } & -0.0254 & 0.2688 \\ \text { INVVA2 } & -0.0625 & 0.3523 \\ \text { INVVA4 } & -0.2259 & 0.6443 \\ \text { INVVA5 } & 0.1918 & 0.3991 \\ \text { INVVA6 } & 2.3688 & 2.1793 \\ \text { INVVA7 } & 0.2783 & 0.2338 \\ \text { DCU1 } & -0.0005 & 0.0483 \\ \text { DCU2 } & 0.0811 & 0.064 \\ \text { DCU4 } & -0.002 & 0.1159 \\ \text { DCU5 } & -0.1427 & 0.0727 \\ \text { DCU6 } & -1.2718 & 0.4144 \\ \text { DCU7 } & -0.0613 & 0.0424\end{array}$

$R^{2}-A D J=0.9817^{a}$

$R^{2}-A D J=0.9894^{a}$

Number of observations $=366$

Reference category is occupation 3, "clerical and related workers".

a The adjusted R-squares are calculated by adjusting Buse's R-squares (see Buse,1973) for the degrees of freedom.

Table 5 gives the estimation results of the occupational model; the columns (B) give the parameter estimates and the standard errors (SD) respectively. The first columns contain the results when only the measurement error is taken into account. The coefficients belonging to the variable INVVA of equation (13) are here denoted as INVVA1, INVVA2, INVVA4 until INVA7 according to the seven occupational groups distinguished. The same holds for the variable DCU. Occupation 3 is missing in the table because this

8. Of course this problem gets more important if more disaggregated data are used. The least (adjusted) number of working people in a industryoccupation-education-combination of the whole sample (the number of existing number of combinations from 1979 to 1985 of the 21 branches of industry, 83 occupations and 58 educations $=36,730$ ) is thirty persons. So the contribution of creating several combinations by assuming one working person instead of zero does not seem too serious. 
occupation ("clerical and related workers") is here chosen to be the reference category (so in equation (13) the coefficients $\beta_{13}$ and $\beta_{23}$ are supposed to be zero). The coefficient of the lagged endogenous variable (LENDO) indicates the importance of the past occupational structure but is also significantly different from 1 (using a critical t-value of 1.96). All other coefficients differ significantly from zero, so according to these results the other variables can not be ignored.

When estimating this model with Modified Multinomial Logit however (see the last columns of table 5) only two coefficients are significantly different from zero. These results resemble the results of Parks (1980) and Van Opstal (1988) by the considerable increase of the standard errors. Parks already concluded that the differences of the standard errors between estimating by SML and MML become larger in case the specification error more dominates the measurement error. Here the specification error indeed seems to play a very big role. However, the industrial-specific variables DCU is not negligible. This can be concluded from table 6 , that contains the F-statistics belonging to the overall significance of both variables within the (general) model (13).

Table 6. F-statistics for the exclusion of variables INVVA and DCU (7 occupations) ${ }^{a}$

\begin{tabular}{lccc}
\hline Excluded variable & F-statistic & Number of restrictions & $\begin{array}{c}\text { Critical value } \\
(5 \%)\end{array}$ \\
\hline INVVA & & 6 & 2.1 \\
DCU & 0.79 & 6 & 2.1 \\
\hline
\end{tabular}

a The F-statistics are calculated using the formula (12) of Buse (1979).

* Significant F-statistics at the 5\%-level.

Because the relevance of changing investments to the occupational structure seems reasonable, the partial effects of the industrial-specific variables are given (separately from the reference category) in table 7 . These are calculated by taking the derivatives of the probabilities with respect to these variables (see (13)), that is

$$
\delta p_{t}(0 \mid b) / \delta x_{j}(b, t)=p_{t}(0 \mid b)\left(\beta_{j 0}-\sum_{i=1}^{0} p_{t}(0 \mid b) \beta_{j i}\right)
$$


where

$j=1$ or $j=2$

$x_{j}=$ INVVA if $j=1$

$x_{j}=D C U$ if $j=2$.

The values calculated in table 7 are the average values of (4.2) over the industries and years.

Table 7. Derivatives of the probabilities with respect to the industrial-specific exogenous variables

\begin{tabular}{lrr}
\hline Occupational category & INVVA & DCU \\
\hline & & 0.007 \\
1. Professional & -0.024 & 0.006 \\
2. Administrative & -0.010 & 0.002 \\
4. Sales & -0.016 & -0.006 \\
5. Services & 0.005 & -0.019 \\
6. Agricultural & 0.034 & -0.003 \\
7. Production & 0.039 &
\end{tabular}

These results contradict in a way our expectations concerning these explanatory variables. If investments expand an increase of the higher qualified employed persons is usually expected. According to these results the higher qualified occupations, that are the first mentioned occupations, are negatively effected by an investments increase whereas the lower qualified occupations (occupational groups 6 and 7 ) benefit from these developments. Remarkably, the degree of capacity utilization shows the opposite signs. However, none of these partial derivative estimates are significant (at the $5 \%$ level).

Annex D.1 contains the results of the occupational model (13) when 83 occupations are distinguished (so index 0 within (13) ranges from 1 to 83). Again the results of Standard Multinomial Logit are presented in the first columns. Contrarily to the "small" occupational model above, this model is not estimated by the Modified Multinomial Logit method that was presented in the preceding chapter. Because of the fact that we distinguish so many occupations, the number of occurring occupations within the 21 branches of industry varies strongly. The estimation of the covariance matrix of the 
specification error (see annex $C(C .1)$ and (C.2)) therefore did not lead to a semi-positive definite matrix. That is why we assume matrix $\Sigma$ to be diagonal instead of full symmetric. The estimation procedure is however further proceeded as the Modified Multinomial Logit method. The estimation results of this method are indicated as MML (-) in annex D.1. The reference used, that is occupation 28 "clerical and related workers", is an occupational group that occurs in every branch of industry.

The results again show a big difference between the standard deviations of both estimation steps. The parameter estimations between both estimation methods also seem very different but can be justified by the insignificance of the individual estimates (most (MML-)parameter estimates are not significant). The lagged endogenous variable plays the biggest role. Even the MML-estimate indicates that the current occupational structure is highly dependent (more than $60 \%$ ) on the past occupational structure and is highly significant. Comparing the lagged variable estimate with the estimate in table 4.1 we see that when distinguishing more occupational groups the lagged variable obviously seems to become less important, perhaps in favor of the other explanatory variables. The individual effects of the investments and degree of capacity utilization are mostly not significant but the overall significance of both variables counts. Table 8 contains the F-statistics belonging to the occupational model with 83 occupations.

Table 8. F-statistics for the exclusion of variables INVVA and DCU ( 83 occupations) ${ }^{a}$

\begin{tabular}{lccc}
\hline Excluded variable & F-statistic & Number of restrictions & $\begin{array}{r}\text { Critical value } \\
(5 \%)\end{array}$ \\
\hline INVVA & $2.24^{*}$ & 82 & 1.29 \\
DCU & $106.12^{*}$ & 82 & 1.29 \\
\hline
\end{tabular}

a The F-statistics are calculated using the formula (12) of Buse (1979).

* Significant F-statistics at the 5\%-leve1.

Contrarily to the "small" occupational model both industrial-specific variables are significant. This overall significance of both variables is possibly due to the fact that the individual effects of the investments and degree of capacity utilization on occupational groups differ (or compensate each other) within the seven occupational categories distinguished in the 
"small" model. The estimation of the individual effects therefore seems sensible ${ }^{9}$.

\subsection{The explanation of the educational shifts within both branches of} industry and occupational groups during 1979-1985

The model explaining the educational structure within branches of industry and occupations is as follows:

$$
\begin{aligned}
\ln \left(f_{t}(e \mid b, o) / f_{t}\left(e^{*} \mid b, o\right)\right)= & \mu \ln \left(f_{t-2}(e \mid b, o) / f_{t-2}\left(e^{*} \mid b, o\right)\right)+ \\
& \sum_{i=1}^{E} \tau_{1 j} \operatorname{INVVA}(b, t)+\sum_{i=1}^{E} \tau_{2 i} \operatorname{DCU}(b, t)+ \\
& \sum_{i=1}^{E} \tau_{3 i} \operatorname{In}\left(\operatorname{PLF}(e, t) / \operatorname{PLF}\left(e^{*}, t\right)\right)+\epsilon_{e b o t}
\end{aligned}
$$

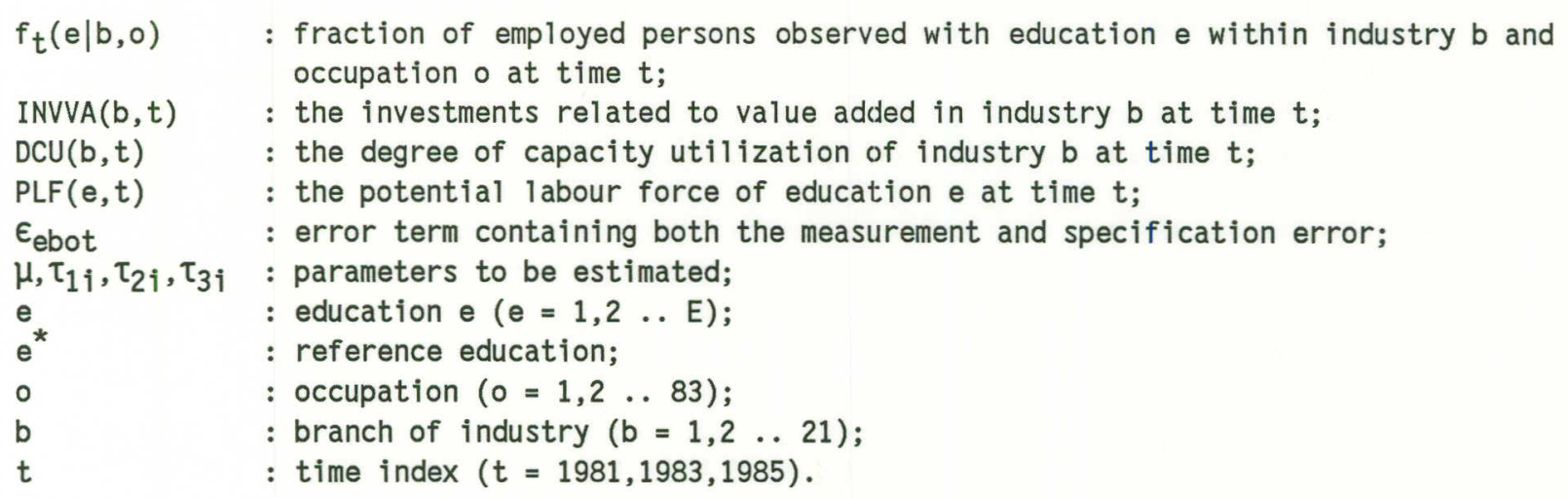

In the model that distinguishes five educational levels the variable PLF is based on the Labour-Force Censuses (see Central Bureau of Statistics (CBS,1985)). If 58 educations are distinguished the variable is calculated by means of table 14 of the so called SKILL-estimates of the Central

9. We also calculated the F-statistics belonging to the SML-estimates. These statistics also showed the higher significance of the industrial-specific variable estimates when more occupational groups were distinguished. So the conclusions here concerning the overall significance of both industrial specific variables do not seem to depend on the different application of the second estimation step, that is the application of the Multinomial Logit (MML versus MML $(-))$. 
Planning Bureau (see Spronk, 1985) ${ }^{10}$.

The estimation results of the model with five educational levels are found in table 9. The reference education is chosen to be the lowest educational level.

Table 9. Estimation results of the educational model (5 educations)

STANDARD MULTINOMIAL LOGIT

\begin{tabular}{|c|c|c|c|c|c|}
\hline & B & SD & & B & SD \\
\hline LENDO & 0.8763 & 0.0005 & LENDO & 0.6203 & 0.0146 \\
\hline INVVA3 & -0.0768 & 0.01 & INVVA3 & 0.4232 & 0.5506 \\
\hline INVVA4 & -0.2431 & 0.0096 & INVVA4 & 0.2721 & 0.5864 \\
\hline INVVA5 & 0.2417 & 0.0123 & INVVA5 & 0.5709 & 0.6681 \\
\hline INVVA6 & 0.1449 & 0.0151 & INVVA6 & 1.3936 & 0.8311 \\
\hline DCU3 & -0.6852 & 0.0137 & DCU3 & -1.1295 & 0.9441 \\
\hline DCU4 & 0.2458 & 0.0091 & DCU4 & 0.3297 & 0.6907 \\
\hline DCU5 & -0.343 & 0.0092 & DCU5 & -1.0778 & 0.5416 \\
\hline DCU6 & -0.1281 & 0.012 & DCU6 & -0.6478 & 0.6881 \\
\hline PLF3 & 0.6714 & 0.0109 & PLF3 & 1.1965 & 0.7499 \\
\hline PLF4 & 0.0352 & 0.007 & PLF4 & 0.2298 & 0.5306 \\
\hline PLF5 & 1.4294 & 0.0237 & PLF5 & 3.2363 & 1.4058 \\
\hline PLF6 & 2.5177 & 0.0955 & PLF6 & 4.293 & 5.5357 \\
\hline \multicolumn{3}{|c|}{$R^{2}-A D J=0.9115^{a}$} & \multicolumn{3}{|c|}{$\mathrm{R}^{2}-\mathrm{ADJ}=0.7557^{\mathrm{a}}$} \\
\hline
\end{tabular}

a The adjusted R-squares are calculated by Buse's R-squares (see Buse,1973) adjusted for the degrees of freedom.

The value of the highly significant parameter estimate of the lagged endogenous variable indicates the rigidity of the educational structure. Beside, the influence of the potential labour force is in line with our expectations. The supply of highly educated persons (educational level 5 and 6) effects the educational structure mostly whereas the medium educational level (level 4) seems to have the least impact on the educational structure. According to these results the investments and degree of capacity utilization show again individually non significant estimates. Table 10 gives the statistics belonging to the overall significance of these variables. According to these results the influence of the variables degree of capacity utilization and the potential labour force should not be neglected.

10. The Central Planning Bureau however distinguishes less than 58 educations so that some educations of the 58 educations are assumed to be affected by the same educational groups. 
Table 10. F-statistics for the exclusion of variables INVVA, DCU and PLF (5 educations) a

\begin{tabular}{lccc}
\hline Excluded variable & F-statistic & Number of restrictions & $\begin{array}{c}\text { Critical value } \\
(5 \%)\end{array}$ \\
\hline INVVA & 1.19 & 4 & 2.37 \\
DCU & $4.44^{*}$ & 4 & 2.37 \\
PLF & $3.02^{*}$ & 4 & 2.37 \\
\hline
\end{tabular}

a The F-statistics are calculated using the formula (12) of Buse (1979).

* Significant F-statistics at the $5 \%$-level.

Table 11 contains the partial derivatives of the probabilities with respect to the explanatory variables. According to these results an increase of the investments effects negatively the secondary educational higher level whereas the degree of capacity utilization effects positively this level. All other levels experience the opposite effects. This secondary educational level is also the only level that does not take any advantage of an increasing labour supply of persons with the same educational level.

Table 11. Derivatives of the probabilities with respect to the industrial-specific exogenous variables and the labour supply variable

\begin{tabular}{lrrr}
\hline Educational category & INVVA & DCU & PLF \\
\hline 3. Secondary education lower & 0.028 & -0.217 & 0.099 \\
4. Secondary education higher & -0.036 & 0.267 & -0.319 \\
5. Higher vocational ed. & 0.018 & -0.102 & 0.259 \\
6. University & 0.057 & -0.017 & 0.170
\end{tabular}

Annex D.2 contains the results of the occupational model, in which 58 occupations are distinguished (so e ranges from 1 to 58 ). From all estimated models this model is mostly effected by the substitution of dummy values for missing lagged endogenous observations (see the first note of this chapter). Because of the high disaggregation within both industries and (highly disaggregated) occupations it is not possible to find an education that occurs within every existing industry-occupation-combination (at each point in time). That is why we have chosen two educations that serve as reference categories. These are the general educational groups 1 "elementary education" and 11 "general secondary education". The category of both educations that is mostly observed overall years within a industryoccupation-combination is chosen to be the reference education. If the 
reference education was not occurring in the past again a dummy value of one employed person was taken instead of zero persons (see also the remark about dummy values in part 4.1 ).

The estimation results in annex D.2 show the highly significant dependence of the past structure. Estimated coefficients of both industrial-specific variables diverge largely within the educational levels distinguished. Shifts within the educational structure explained by the investments and degree of capacity utilization are however individually not significant according to the MML-estimation results. Contrarily the estimated coefficients of the labour supply variable does not diverge that much over all educations distinguished. As a consequence this variable does not show the different influences of the labour supply on the educational levels, which could have been expected according to the estimation results of table 9. Probably the estimation results of the more disaggregated model are largely influenced by the educational groups within the educational levels that are well represented within the sample.

Table 12. F-statistics for the exclusion of variables INVVA, DCU and PLF (58 educations) ${ }^{a}$

\begin{tabular}{lccc} 
Excluded variable & F-statistic & Number of restrictions & $\begin{array}{c}\text { Critical value } \\
(5 \%)\end{array}$ \\
\hline INVVA & $3.34^{*}$ & 56 & 1.34 \\
DCU & $21.42^{*}$ & 56 & 1.34 \\
PLF & $24.02^{*}$ & 52 & 1.35 \\
\hline
\end{tabular}

a The F-statistics are calculated using the formula (12) of Buse (1979).

* Significant F-statistics at the 5\%-level.

The F-statistics of this model are given in table 12. The three explanatory variables are according to these results overall significant, so that the explanatory contribution of these variables to the educational structure should not be neglected.

\subsection{A comparison of the Fixed Coefficient results with the Multinomial Logit results}

In this chapter the occupational and educational shares of persons employed within branches of industry and both branches of industry and occupations respectively are explained by economic explanatory variables. Here we 
compare these results with the results of the fixed coefficient method. In annex $B$ the results of a shift and share analysis of the occupational model (with seven occupations) are given in table B.1. Column 4 contains the results of the fixed coefficient method in which the occupational structure of 1979 is imposed upon the total numbers of employed persons within the 21 branches of industry in 1985. By means of the estimation results of the SMLand the MML-method we calculated the estimated numbers of employed persons within the seven occupations. These estimated numbers and the numbers of the fixed coefficient method are compared with the real numbers of employed persons in 1985. We calculated the average absolute deviation of the estimated numbers from the real numbers per occupation in 1985 with respect to the total numbers of persons employed in 1985, that is

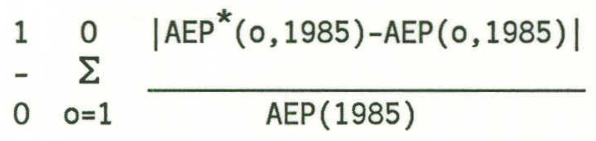

where

$0 \quad:$ total number of occupations;

$\operatorname{AEP}(0,1985)$ : number of employed persons with occupation 0 in 1985;

$\operatorname{AEP}^{*}(0,1985)$ : estimated number of employed persons with occupation 0 in 1985;

$\operatorname{AEP}(1985) \quad$ : total number of employed persons in $1985\left(=\Sigma_{0} \operatorname{AEP}(0,1985)\right)$.

Table 13 gives the calculated criterions (4.4) for all estimation results and all models (where the criterion in (4.4) is summed over educations instead of occupations within the educational models).

Table 13. Comparing the estimation results of the Fixed Coefficient Method (FCM) with the Multinomial Logit results (SML and MML)

\begin{tabular}{llcc}
\hline & FCM & SML & MML/MML(-) \\
\hline Occupational model (7 occupations) & 0.0066 & 0.0034 & 0.0051 \\
Educational model (5 educational leve1s) & 0.0352 & 0.0011 & 0.0118 \\
Occupational model (83 occupations) & 0.0010 & 0.0006 & 0.0037 \\
Educational model (58 educations) & 0.0039 & 0.0013 & 0.0038 \\
\end{tabular}

a The more aggregated models were estimated with MML(-).

The first row in table 13 shows the results of the highly aggregated occupational model. We see that the SML-result is much better than the FCMresult, that is the FCM-result shows an average deviation which is twice the 
SML-result. Although the MML-result is still better than the FCM-result, the difference between both results is much smaller. Here all models show better SML- than FCM-results. However, according to this criterion results are not improved by taking account of the specification errors; the MML-results are worse than the SML-results and the MML-result even exceeds the FCM-result within the highly disaggregated occupational model. However, within this occupational model the fixed coefficient method seems rather good with respect to the other three models. Unfortunately according to these results we still can not draw any definite conclusions about the estimation method multinomial logit compared with the fixed coefficient method. Here only one simple criterion is used and just one year, 1985, is taken into account. Because the FCM-results of the highly disaggregated models indicate much better results than the more aggregated models, these results justify the fact that the assumption of the rigidity of the occupational and educational structure seems significant so that the dependence on past structures should always be considered. 



\section{CONCLUSIONS}

In this study the occupational structure of 83 occupations was explained by the past occupational structure and the investments and degree of capacity utilization within 21 branches of industry. The estimation results indicated the major significance of the past occupational structure but also the overall non-negligence of both industry-specific variables.

In this study also the educational structure of 58 educations within the occurring combinations of the 21 branches of industry and 83 occupations was examined. Besides the past educational structure and the industry-specific variables, investments and degree of capacity utilization, the labour supply variable "potential labour force" was used for explaining the present educational structure. Like in the occupational model, the past educational structure played a highly significant role. Moreover, the three other exogenous variables are overall significant.

However, of course some remarks of criticism have to be made. Firstly, the serious and seemingly insurmountable problem we encountered was the lacking of past observations. The results of the shift and share method (chapter 2) indicated that the past structures should be taken into account. Because we chose a specification that contained a logarithmic transformed lagged endogenous variable the problem of missing observations arose. We solved this problem by substituting the past zero observations of presently occurring occupations or educations by one employed person (with this certain occupation or education). We expect that this artificial solution to the problem does not influence the estimation results in a significant way because of the relatively small contribution of these "created" numbers.

The second problem concerns the fact that the estimation method used was not fully executed as described by Parks (the introducer of the method used). Both the occupational and educational model were estimated by Standard Multinomial Logit and should in a second stage be estimated by Modified Multinomial Logit. Both the measurement and the specification error would then be taken into account respectively. We did not succeed in executing the Modified Multinomial Logit method because of the fact that the covariance matrix of the specification error was found to be indefinite. We therefore estimated this matrix by assuming it to be diagonal so we extended the Standard Multinomial Method but modified the Modified Multinomial Method. 
A third problem was encountered when estimating the educational structure within branches of industry and occupations. Because we here wanted to use the Multinomial Logit Method again there had to be an education to serve as a reference category. It was impossible to find an educational category that occurred within all branches of industry and occupations, so again adjustments had to be made by replacing a lacking past reference education by a dummy value of one employed person.

Beside these above critical remarks on the estimation procedure, improvements could be made with regards to the exogenous variables used. The lagged endogenous variable seems to fit well and seems to dominate the other explanatory variables. Possibly occupational specific variables like the average wages of each occupational category could improve the explanatory power of these variables of the occupational model. The educational model possesses already an educational-specific variable, namely the potential labour force, but the differentiation of this variable could also be better extended according to the 58 educations distinguished.

In comparison with the preceding studies of Dekker et al. (1988) and Beekman et al (1989) within the Research Centre for Education and Labour Market this study differs mainly in the estimation method used. Dekker et al. explained the occupational structure within branches of industry by means of Weighted Least Squares, where Beekman et al. used the same estimation method when explaining the educational structure within both industries and occupations. Both studies explained observed fractions of working persons that were not related to a reference category. Therefore estimated fractions had to be adjusted afterwards to maintain the logical consistency that all fractions (occupations within industries and educations within both industries and occupations) add up to one. Logical consistency is maintained in this study by means of the reference category used. Also because of this logical consistency a specific structure of the covariance matrix was taken into account. Another difference between this study and both studies mentioned above is that in this study past structures were used as explanatory variables. According to the theory and also according to our estimation results these lagged structures seem to play an important role, although the role of the other explanatory variables that ought to explain the structure shifts should of course not be neglected. The coefficient estimates of the other explanatory variables are of course determined by the (relatively high) coefficient estimate of the lagged endogenous variable. Probably the 
long term coefficient estimates, that could be calculated by assuming the endogenous and the lagged endogenous variable to be the same, will indicate the importance of these variables.

Like most previous studies, this study could be improved by more and better data. The Labour-Force Censuses we used only contain four years. Because of the econometric specification chosen, only the occupational and educational structure of three years (1981, 1983 and 1985) could be considered. The relative importance of the time aspect of the lagged endogenous variable within the specification certainly asks for a longer time-period of analysis. If the occupational and educational structures at more points of time are analyzed, and possibly more fluctuations over this longer time period are found, the other exogenous variables used could probably account for more explanatory power. Moreover, of course more recent data are more interesting for analyzing latest developments of the occupational and educational structures. 



\section{REFERENCES}

Beekman, Th.B.J., R.J.P. Dekker, A. de Grip and J.A.M. Heijke (1989), An explanation of the educational structure of occupations, ROA-W-1989/3E, Maastricht.

Bekkering, J.M., J.S. Cramer and M.J. Ghering (1988), De werkgelegenheid per beroepsgroep, Stichting voor Economisch Onderzoek, Amsterdam.

Buse, A. (1973), Goodness-of-Fit in Generalized Least Squares Estimation, The American Statistician, vol. 27 no. 3, p. 106-108.

Buse, A. (1979), Goodness-of-Fit in the Seemingly Unrelated Regressions Mode1, A Generalization, Journal of Econometrics, p. 109-113.

Centraal Bureau voor de Statistiek, Arbeidskrachtentelling 1979-1985.

Dekker, R.J.P., A. de Grip and J.A.M. Heijke (1988), An explanation of the occupational structure of sectors of industry, ROA-W-1988/2E, Maastricht.

Freeman, R.B. (1980), An empirical analysis of the fixed coefficient "manpower requirements" model, 1960-1970, The Journal of Human Resources 15, p. 176-199.

Freeman, R.B. (1986), Demand for education, in 0.C. Ashenfelter and R. Layard (eds.), Handbook of Labor economics, Vol. I, North-Holland, Amsterdam.

Grip, A. de (1987), Winnaars en verliezers op de arbeidsmarkt 1981-1985, Tijdschrift voor Arbeidsvraagstukken, jaargang $3 \mathrm{nr}$. 4, p. 61-69.

Grip, A. de, J.A.M. Heijke and R.J.P. Dekker (1989), The labour market by education and occupation in 1992, ROA-R-1989/8E, Maastricht.

Groot, L.F.M., J.A.M. Heijke (1989), Een verklaring van arbeidsduur en deeltijdarbeid naar beroep en bedrijfstak, ROA-W-1989/2, Maastricht.

NEI, Een verkenning van de arbeidsmarkt naar beroep en opleiding tot 1990, Organisatie voor Strategisch Arbeidsmarktonderzoek, OSA-Werkdocument $\mathrm{nr}$. W17, Zoetermeer, 1986.

Opstal, R.M. van (1988), Estimation of manpower coefficients with a modified multinomial logit method, CPB, no. 41, 's Gravenhage.

Parks, R.W. (1980), On the estimation of multinomial logit models from relative frequency data, Journal of Econometrics 13, 292-303.

ROA, Het informatiesysteem onderwijs-arbeidsmarkt, onderzoekprogramma 1990/1991, Researchcentrum voor Onderwijs en Arbeidsmarkt, ROA-R-1990/4, Maastricht, 1990.

Singelmann, J., H.L. Browning (1980), Industrial transformation and occupational change in the U.S., Social Forces, volume 59, p. 246-264.

Spronk, R.M. (1985), Tijdreeksen uit de onderwijsprognose 1985, Centraal Planbureau, notitie 12 . 
$-35-$

Teulings, C.N., H.D. Webbink (1990), Verschuivingen in werkgelegenheidstructuren, Economische Statistische Berichten, p. 469-472. 
ANNEX A: Branches of industry, occupational and educational groups

ANNEX A.1.: Branches of industry codes and corresponding names

INDEX AGRICULTURE \& MANUFACTURING INDUSTRY

$\begin{aligned} 1 & \begin{array}{l}\text { Agriculture, fishing, forestry } \\ 2\end{array} \\ 3 & \begin{array}{l}\text { Manufacture of foodstuffs, beverages, } \\ \text { tobacco products }\end{array} \\ 4 & \begin{array}{l}\text { Manufacture of textiles, wearing appare1, } \\ \text { footwear and other leather products }\end{array} \\ 5 & \begin{array}{l}\text { Manufacture of wood and building materials } \\ \text { Manufacture of paper and printing and publishing } \\ \text { industries }\end{array} \\ 6 & \begin{array}{l}\text { Petroleum, chemical industry and manufacture of } \\ \text { rubber and plastic products }\end{array} \\ 8 & \begin{array}{l}\text { Basic metal industries } \\ \text { Manufacture of metal products, mechanical and } \\ 9\end{array} \\ 10 & \begin{array}{l}\text { Electrical engineering } \\ \text { Manufacture of transport equipment }\end{array} \\ 11 & \begin{array}{l}\text { Mining and quarrying } \\ \text { Electricity, gas and water }\end{array} \\ 13 & \text { Construction }\end{aligned}$

CODE

01-03

20-21

$22-24$

25,32

$26-27$

28-31

33

$34,35,38,39$

36

37

$11,12,19$

40

51,52

\section{TERIARY \& QUATERNARY SERVICES}

14 Trade (wholesale and retail)

15 Sea- and airtransport

16 Transport, storage and communication

17 Banking and insurances

18 Other private services and ownership of dwellings

19 Medical and veterinary services

20 Other public services

$61,62,65,66$

73,75

$71,72,74,76,77$

81,82

$67,68,83-85,98,99$

93

$91,94-97$

\section{GOVERNMENT}

21 Public administration and education

90,92 
ANNEX A.2.: Occupational codes and corresponding names

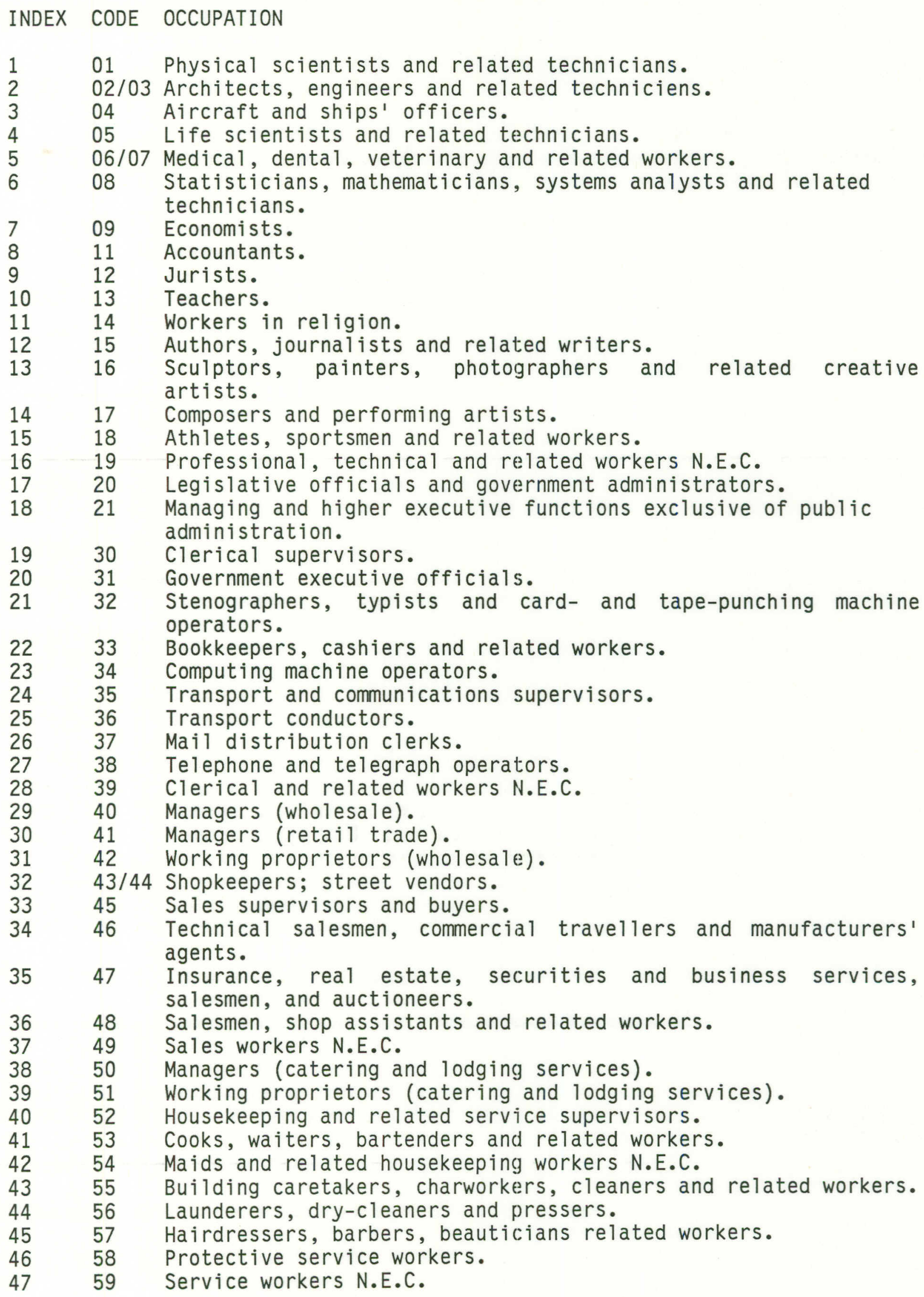




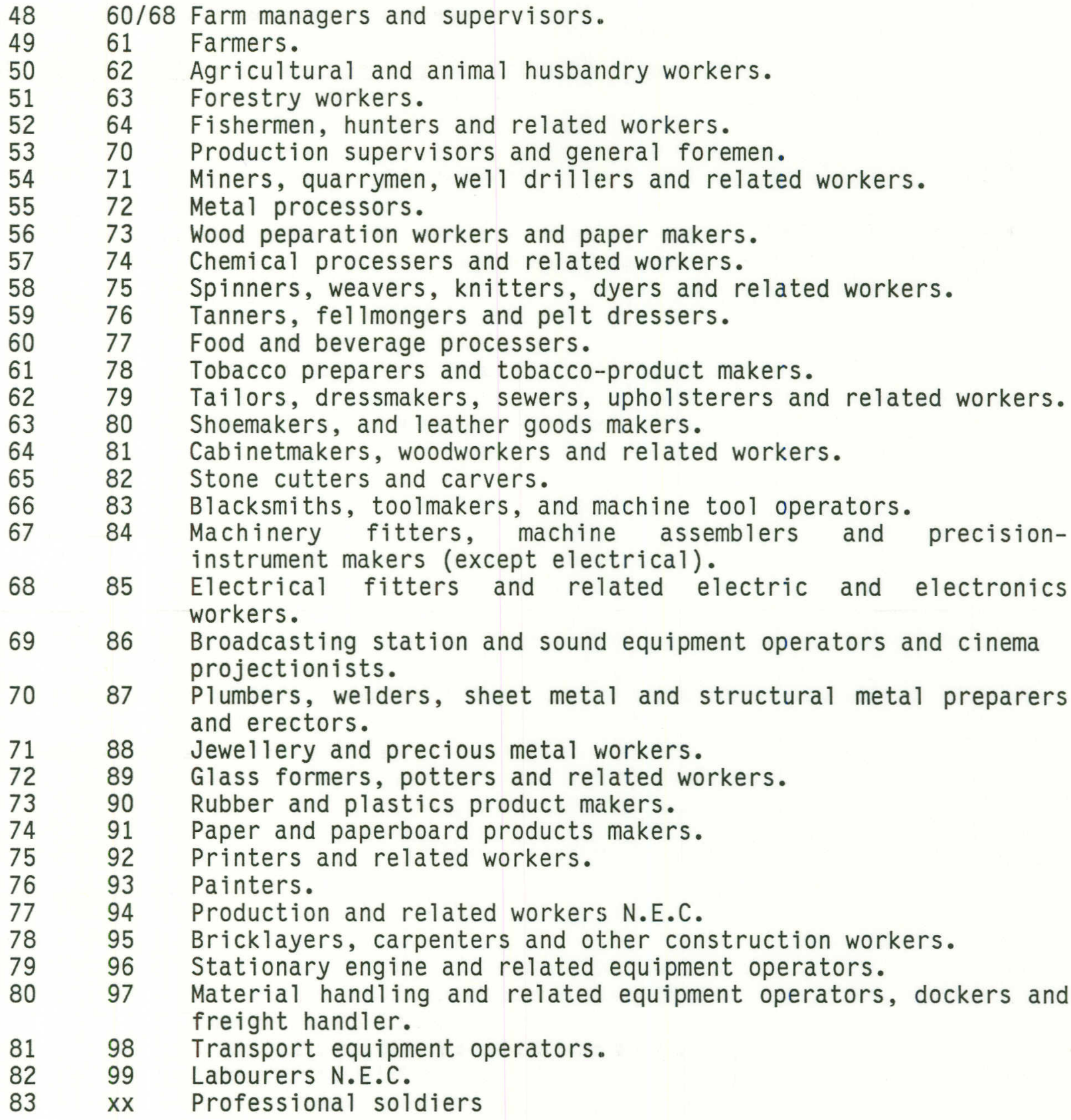


ANNEX A.3.: Educational codes and corresponding names

IND CODE

Educational level 2: Primary education

$1000,111,201$

Educational level 3:

EDUCATION

$8 \quad 381-386$

9 391-394

10 other

Educational level 4:

$\begin{array}{ll}11 & 401 \\ 12 & 406 \\ 13 & 421-429 \\ 14 & 431-439 \\ 15 & 441-449 \\ 16 & 451\end{array}$

$17 \quad 452$

$18 \quad 454$

$19453,461-464$

$20 \quad 466$

$21 \quad 471$

$22481,484-486$

$23 \quad 483$

$24 \quad 491-494$

25 other

Elementary education

Secondary education (lower level)

General secondary education, lower level

Junior agricultural education

Junior technical education

Junior transport, communication and traffic education

Junior medical and paramedical education

Lower business education, Secondary school for tradesmen (lower level), Practical training for clerks and salesmen at the school for domestic science and technique

School for domestic science and technique exclusive of training for clerks and salesmen, establishment certificate for café holders

Business security and surveillance training

Other disciples at educational level 3

Secondary education (higher level)

General secondary education, intermediate and higher levels

Training for driving instructor, sports coach

Senior agricultural education

Senior school for laboratory science and senior technical training

Senior education in transportation, communication and traffic science

Training of nurses and medical receptionists at the secondary school for medical and other services, higher level

Secondary school for medical laboratory science, higher level

Training for ward orderlies, etc.

Training for medical clerks, senior retail school and intermediate business education, etc.

Intermediate business education, department of management studies

Social work and welfare work (secondary school for medical and other services)

External care, services as taught at the secondary school for medical and other services or the INTAS, fashion drawing, etc

Secondary hotel and catering school, hairdresser's school

Training of municipal and state police, fire brigade

Other disciplines at educational level 4 

ANNEX B: Shift and share analysis

ANNEX B.1.: Changes in the occupational structure and its components, 1979-1985

Table B.1. Changes in the occupational structure and its components, 1979-1985

\begin{tabular}{|c|c|c|c|c|c|c|c|}
\hline & 1 & 2 & 3 & 4 & 5 & & \\
\hline Profess. & 783080 & 914660 & 776423 & 874802 & 817099 & & \\
\hline Administ. & 113663 & 159564 & 112697 & 111882 & 166038 & & \\
\hline Clerical & 809384 & 826548 & 802503 & 824651 & 803023 & & \\
\hline Sales & 442821 & 438119 & 439056 & 428044 & 450871 & & \\
\hline Services & 386447 & 402910 & 383162 & 434894 & 354579 & & \\
\hline Agricult. & 267484 & 250744 & 265210 & 253258 & 262080 & & \\
\hline Product. & 1531391 & 1304877 & 1518372 & 1369890 & 1443732 & & \\
\hline \multirow[t]{2}{*}{ Total } & 4334270 & 4297422 & 4297423 & 4297421 & 4297422 & & \\
\hline & 6 & 7 & 8 & 9 & 10 & 11 & 12 \\
\hline Profess. & 138237 & 98379 & 40676 & -818 & 71.17 & 29.42 & -0.59 \\
\hline Administ. & 46867 & -815 & 53341 & -5659 & -1.74 & 113.81 & -12.07 \\
\hline Clerical & 24045 & 22148 & 520 & 1377 & 92.11 & 2.16 & 5.73 \\
\hline Sales & -937 & -11012 & 11815 & -1740 & 1175.24 & -1260.94 & 185.7 \\
\hline Services & 19748 & 51732 & -28583 & -3401 & 261.96 & -144.74 & -17.22 \\
\hline Agricult. & -14466 & -11952 & -3130 & 616 & 82.62 & 21.64 & -4.26 \\
\hline Product. & -213495 & -148482 & -74640 & 9627 & 69.55 & 34.96 & -4.51 \\
\hline
\end{tabular}

Column 1 : Column 2 : Column 3 :

Column 4 :

Column 5 :

Column 6 :

Column 7 :

Column 8 :

Column 9 :

Column 10 :

Column 11 :

Column 12 :
Adjusted number of employed persons in 1979;

Adjusted number of employed persons in 1985;

Adjusted number of employed persons in 1985 if the occupational structure of 1979 is applied to the total adjusted number of employed persons in 1985;

Adjusted number of employed persons in 1985 if the occupational within industries of 1979 is applied to the adjusted number of employed persons within industries in 1985;

Adjusted number of employed persons in 1985 if the industrial structure effect of 1979 is applied to the total number of employed persons in 1985 with the occupational structure of 1985;

Change in occupational structure because of industry and occupational shifts, called the net shift (= column 2 - column 3 );

Change in occupational structure because of industry changes, called the industry shift effect (= column 4 - column 3 );

Change in occupational structure because of occupational structure changes within industries, called the occupational shift effect (= column 5column 3);

Changes in occupational structure as a consequence of changes in both occupational and industrial shifts that are not directly attributable to one of both effect, called the interaction effect (= column 6 - column 7column 8);

Share of the industrial shift in the total shift (= column 7 divided by column 6);

Share of the occupational shift in the total shift (= column 8 divided by column 6);

Share of the interaction shift in the total shift (= column 9 divided by column 6). 
The columns 10 until 12 previously mentioned are here given for 83 occupations within 21 industries (see annexes A.2 and A.1).

Table B.2. Percent changes in the occupational structure and its components, 1979-1985

\begin{tabular}{|c|c|c|c|c|c|c|c|}
\hline Occ. & $\begin{array}{l}\text { Industry } \\
\text { shift } \\
\text { effect }\end{array}$ & $\begin{array}{l}\text { Occ. } \\
\text { shift } \\
\text { effect }\end{array}$ & $\begin{array}{l}\text { Inter. } \\
\text { effect }\end{array}$ & Occ. & $\begin{array}{l}\text { Industry } \\
\text { shift } \\
\text { effect }\end{array}$ & $\begin{array}{l}\text { Occ. } \\
\text { shift } \\
\text { effect }\end{array}$ & $\begin{array}{l}\text { Inter. } \\
\text { effect }\end{array}$ \\
\hline 1 & 297.91 & -98.96 & -98.96 & 42 & 691.24 & -628.68 & 37.44 \\
\hline 2 & -44.14 & 32.71 & 111.43 & 43 & 71.72 & 47.49 & -19.21 \\
\hline 3 & 86.80 & 13.64 & -0.44 & 44 & -137.98 & 178.79 & 59.19 \\
\hline 4 & 50.39 & 38.41 & 11.20 & 45 & -1070.97 & 1095.16 & 75.81 \\
\hline 5 & 82.73 & 13.13 & 4.14 & 46 & 47.86 & 48.66 & 3.48 \\
\hline 6 & 5.52 & 88.69 & 5.79 & 47 & -685.34 & 672.28 & 113.06 \\
\hline 7 & 19.64 & 84.47 & -4.11 & 48 & -2.14 & 110.8 & -8.66 \\
\hline 8 & 207.52 & -101.00 & -6.52 & 49 & 65.93 & 36.09 & -2.02 \\
\hline 9 & 16.10 & 75.18 & 8.72 & 50 & 64.56 & 43.44 & -7.99 \\
\hline 10 & 82.77 & 14.43 & 2.80 & 51 & 35.04 & 80.47 & -15.51 \\
\hline 11 & 178.37 & -58.37 & -20.00 & 52 & -12.15 & 116.05 & -3.90 \\
\hline 12 & 5.88 & 87.04 & 7.07 & 53 & -213.98 & 314.24 & -0.27 \\
\hline 13 & -213.67 & 225.95 & 87.72 & 54 & -68.77 & 144.52 & 24.25 \\
\hline 14 & 232.91 & -110.71 & -22.20 & 55 & 20.16 & -0.79 & 80.63 \\
\hline 15 & -568.90 & 570.23 & 98.66 & 56 & 27.12 & 73.55 & -0.68 \\
\hline 16 & 75.46 & 26.37 & -1.83 & 57 & 266.23 & -125.58 & -40.65 \\
\hline 17 & -89.61 & 168.12 & 21.50 & 58 & 59.44 & 50.97 & -10.4 \\
\hline 18 & -2.50 & 114.29 & -11.78 & 59 & 790.91 & -624.24 & -66.67 \\
\hline 19 & -55.64 & 137.71 & 17.93 & 60 & 85.20 & 11.10 & 3.70 \\
\hline 20 & -42.15 & 130.77 & 11.39 & 61 & 58.76 & 46.19 & -4.95 \\
\hline 21 & 92.26 & 9.83 & -2.09 & 62 & 100.71 & -21.74 & 21.03 \\
\hline 22 & 24.11 & 60.83 & 15.07 & 63 & 127.47 & -72.16 & 44.69 \\
\hline 23 & -59.24 & 155.10 & 4.14 & 64 & 55.88 & 54.04 & -9.92 \\
\hline 24 & 6.62 & 103.59 & -10.21 & 65 & -173.58 & 374.53 & -100.94 \\
\hline 25 & 15.22 & 85.75 & -0.97 & 66 & 30.50 & 86.83 & -17.33 \\
\hline 26 & -9.48 & 105.31 & 4.17 & 67 & 35.48 & 70.52 & -6.00 \\
\hline 27 & -40.75 & 121.96 & 18.79 & 68 & -234.57 & 423.43 & -88.86 \\
\hline 28 & 97.63 & -12.94 & 15.31 & 69 & 12.62 & 70.73 & 16.65 \\
\hline 29 & -4.14 & 107.12 & -2.98 & 70 & 51.37 & 42.85 & 5.78 \\
\hline 30 & -12.82 & 115.49 & -2.67 & 71 & -38.46 & 84.62 & 53.85 \\
\hline 31 & -862.86 & 937.14 & 25.71 & 72 & 136.70 & -72.04 & 35.34 \\
\hline 32 & 21.25 & 81.72 & -2.97 & 73 & 416.49 & -288.92 & -27.57 \\
\hline 33 & 34.67 & 61.85 & 3.48 & 74 & -30.96 & 129.56 & 1.40 \\
\hline 34 & -111.10 & 261.02 & -49.92 & 75 & 99.33 & -19.24 & 19.92 \\
\hline 35 & 18.52 & 81.43 & 0.05 & 76 & 78.27 & 24.49 & -2.76 \\
\hline 36 & 145.53 & -71.42 & 25.90 & 77 & 41.13 & 62.59 & -3.72 \\
\hline 37 & -3.97 & 101.87 & 2.10 & 78 & 80.74 & 27.17 & -7.91 \\
\hline 38 & -37.93 & 117.89 & 20.03 & 79 & 27.43 & 103.44 & -30.87 \\
\hline 39 & -218.19 & 288.08 & 30.11 & 80 & 253.11 & -100.28 & -52.84 \\
\hline 40 & 49.64 & 36.38 & 13.98 & 81 & 40.42 & 67.46 & -7.88 \\
\hline \multirow[t]{2}{*}{41} & 492.62 & -349.86 & -42.75 & 82 & 41.29 & 72.76 & -14.04 \\
\hline & & & & 83 & -122.89 & 204.02 & 18.87 \\
\hline
\end{tabular}


$-43-$

ANNEX B.2.: Changes in the educational structure and its components, $\underline{1979-1985}$

Table B.3. Changes in educational structure and its components, 1979-1985

\begin{tabular}{|c|c|c|c|c|c|c|c|}
\hline & 1 & 2 & 3 & 4 & 5 & & \\
\hline Primary & 967962 & 593387 & 959733 & 885726 & 645925 & & \\
\hline Secondary 1. & 1368124 & 1210803 & 1356493 & 1296436 & 1282790 & & \\
\hline Secondary $\mathrm{h}$. & 1421682 & 1728228 & 1409596 & 1446934 & 1704443 & & \\
\hline Higher & 423422 & 558105 & 419822 & 486247 & 490316 & & \\
\hline University & 153080 & 206900 & 151779 & 181877 & 173842 & & \\
\hline \multirow[t]{2}{*}{ Total* } & 4334270 & 4297423 & 4297423 & 4297220 & 4297316 & & \\
\hline & 6 & 7 & 8 & 9 & 10 & 11 & 12 \\
\hline Primary & -366346 & -74007 & -313808 & 21469 & 20.2 & 85.66 & -5.86 \\
\hline Secondary 1. & -145690 & -60057 & -73703 & -11930 & 41.22 & 50.59 & 8.19 \\
\hline Secondary $\mathrm{h}$. & 318632 & 37338 & 294847 & -13553 & 11.72 & 92.54 & -4.25 \\
\hline Higher & 138283 & 66425 & 70494 & 1364 & 48.04 & 50.98 & 0.99 \\
\hline University & 55121 & 30098 & 22063 & 2960 & 54.6 & 40.03 & 5.37 \\
\hline
\end{tabular}

* The sums of the columns 4 and 5 do not equal the sum of column 3 because of the occurrence of industry-occupation-combinations that do not exist in 1979 but do exist in 1985 . 
The columns 10 until 12 previously mentioned (see annex B.1) are here given for 58 educations within 83 occupations and 21 industries (see annexes A.1 until A.3).

Table B.4. Percent changes in the educational structure and its components, 1979-1985

\begin{tabular}{|c|c|c|c|c|c|c|c|}
\hline Edu. & $\begin{array}{l}\text { Ind-occ. } \\
\text { shift } \\
\text { effect }\end{array}$ & $\begin{array}{l}\text { Edu. } \\
\text { shift } \\
\text { effect }\end{array}$ & $\begin{array}{l}\text { Inter. } \\
\text { effect }\end{array}$ & Edu. & $\begin{array}{l}\text { Ind-occ. } \\
\text { shift } \\
\text { effect }\end{array}$ & $\begin{array}{l}\text { Edu. } \\
\text { shift } \\
\text { effect }\end{array}$ & $\begin{array}{l}\text { Inter. } \\
\text { effect }\end{array}$ \\
\hline 1 & 11.72 & 84.70 & 3.57 & 30 & 15.94 & 69.96 & 14.09 \\
\hline 2 & -212.77 & 140.63 & 172.14 & 31 & 1.45 & 56.03 & 42.52 \\
\hline 3 & 25.94 & 63.97 & 10.10 & 32 & 322.31 & -259.30 & 36.98 \\
\hline 4 & 57.65 & 20.42 & 21.93 & 33 & 30.51 & 51.57 & 17.92 \\
\hline 5 & -0.24 & 107.31 & -7.07 & 34 & 22.22 & 63.01 & 14.78 \\
\hline 6 & -36.39 & 102.08 & 34.31 & 35 & 32.86 & 56.70 & 10.44 \\
\hline 7 & 4.34 & 102.63 & -6.97 & 36 & 4.77 & 72.64 & 22.59 \\
\hline 8 & -70.54 & 98.59 & 71.95 & 37 & 1.85 & 71.16 & 27.00 \\
\hline 9 & 4.41 & 80.07 & 15.52 & 38 & 21.42 & 92.06 & -13.48 \\
\hline 10 & 1.49 & 105.60 & -7.09 & 39 & 32.19 & 53.53 & 14.28 \\
\hline 11 & 19.73 & 68.88 & 11.39 & 40 & 50.10 & 60.24 & -10.34 \\
\hline 12 & 123.03 & 54.77 & -77.8 & 41 & 120.27 & 55.66 & -75.93 \\
\hline 13 & -13.42 & 116.80 & -3.38 & 42 & 531.71 & 467.07 & -898.78 \\
\hline 14 & -283.44 & 416.68 & -33.24 & 43 & -40.53 & 134.56 & 5.97 \\
\hline 15 & 10.50 & 94.89 & -5.39 & 44 & 30.03 & 52.84 & 17.13 \\
\hline 16 & 100.04 & 10.31 & -10.35 & 45 & 24.53 & 53.70 & 21.77 \\
\hline 17 & 14.93 & 37.25 & 47.82 & 46 & 53.49 & 56.51 & -10.00 \\
\hline 18 & 40.05 & 49.2 & 10.75 & 47 & 17.45 & 58.59 & 23.96 \\
\hline 19 & 0.66 & 89.45 & 9.89 & 48 & 122.82 & -85.55 & 62.73 \\
\hline 20 & 178.68 & 57.97 & -136.65 & 49 & 21.80 & 62.21 & 15.99 \\
\hline 21 & 43.71 & 50.81 & 5.48 & 50 & 96.60 & -4.95 & 8.35 \\
\hline 22 & 34.15 & 77.21 & -11.37 & 51 & -44.04 & 170.64 & -26.61 \\
\hline 23 & 47.87 & 116.13 & -64.00 & 52 & 24.52 & 31.29 & 44.20 \\
\hline 24 & 24.65 & 74.78 & 0.56 & 53 & 0.52 & 81.56 & 17.92 \\
\hline 25 & -7.11 & 102.57 & 4.54 & 54 & 16.60 & 34.57 & 48.83 \\
\hline 26 & 77.70 & 11.68 & 10.62 & 55 & 16.62 & 66.88 & 16.50 \\
\hline 27 & 40.15 & 1.72 & 58.13 & 56 & -302.00 & 378.00 & 24.00 \\
\hline 28 & 422.16 & -111.34 & -210.82 & 57 & 17.09 & 118.80 & -35.90 \\
\hline 29 & 8.86 & 25.42 & 65.72 & 58 & -29.28 & 132.63 & -3.35 \\
\hline
\end{tabular}


ANNEX C: Estimation of the Multinomial Logit model ${ }^{11}$

For describing the estimation method we recall equation (11) (where we assume $\tau_{j}$ * to be zero)

$$
\ln \left(f_{t}(i \mid g) / f_{t}(0 \mid g)\right)=\alpha \ln \left(f_{t-2}(i \mid g) / f_{t-2}(0 \mid g)\right)+x_{g t}^{\top} \beta_{i}+x_{i t}^{\top} \tau_{i}+e_{i g t}-e_{0 g t}+w_{i g t}
$$

and define :

$i=1,2 \ldots I$

$g=1,2 \ldots G$

$t=2,3 \ldots T 12$

0 : reference labour category

$y=\left[\begin{array}{c}y_{12} \\ y_{22} \\ \cdot \\ y_{G-1, T} \\ y_{G T}\end{array}\right] \quad$ where $\quad y_{g t}=\left[\begin{array}{c}\ln \left(f_{t}(1 \mid g) / f_{t}(0 \mid g)\right) \\ \ln \left(f_{t}(2 \mid g) / f_{t}(0 \mid g)\right) \\ \ln \left(f_{t}(I \mid g) / f_{t}(0 \mid g)\right)\end{array}\right]$

$\mathrm{X}=\left[\begin{array}{lll}\mathrm{y}_{11} & \mathrm{x}_{12} & \mathrm{x}_{2} \\ \mathrm{y}_{21} & \mathrm{x}_{22} & \mathrm{x}_{2} \\ \dot{y}_{\mathrm{G}-1, T-1} & \dot{x}_{\mathrm{G}-1, T} & \dot{x}_{\mathrm{T}} \\ \mathrm{y}_{\mathrm{G}, \mathrm{T}-1} & \mathrm{x}_{\mathrm{GT}} & \mathrm{x}_{\mathrm{I}}\end{array}\right]$

where $x_{g t}$ equals the IxI-diagonal matrix with on the diagonal the elements $\mathrm{xgt}$

and $x_{t}=\left[\begin{array}{ccc}x_{1 t} & & 0 \\ \cdot & \cdot & \cdot \\ \cdot & & \cdot \\ 0 & & x_{I t}\end{array}\right]$

11. See also Parks (1980) or Van Opstal (1988) for a complete description of Modified Multinomial Logit.

12. Because we use a lagged dependent variable the index time ranges from 2 to T. 
$\beta=\left(\alpha, \beta_{1} \ldots \beta_{I}, \tau_{1} \ldots \tau_{I}\right)^{\top}$

$v_{g t}=\left[\begin{array}{c}v_{1 g t} \\ v_{2 g t} \\ v_{\text {Igt }}\end{array}\right] \quad e_{g t}=\left[\begin{array}{c}e_{1 g t}-e_{0 g t} \\ e_{2 g t}-e_{0 g t} \\ \cdot \\ e_{\text {Igt }}-e_{0 g t}\end{array}\right] \quad w_{g t}=\left[\begin{array}{c}w_{1 g t} \\ w_{2 g t} \\ \cdot \\ w_{\text {Igt }}\end{array}\right]$ where $v_{\text {igt }}=e_{\text {igt }}-e_{0 g t}+w_{\text {igt }}$

Further we define the block-diagonal covariance matrix

$V=\left[\begin{array}{cccc}W_{12}+\Sigma & & & 0 \\ \cdot & W_{22}+\Sigma & & \cdot \\ \cdot & \cdot & & \cdot \\ \cdot & & W_{G-1, T}+\Sigma & \cdot \\ 0 & & & W_{G T}+\Sigma\end{array}\right]$

The covariance matrix of the specification error is given by

$$
\begin{aligned}
E\left(\left(e_{g t}-e_{0 t}\right)\left(e_{g^{\prime}} t^{\prime}-e_{0 t^{\prime}}\right)^{\top}\right) & =\Sigma \quad \text { if } g=g^{\prime} \text { and } t=t^{\prime} \\
& =0 \quad \text { else }
\end{aligned}
$$

and the covariance matrices of the measurement errors are

$$
\begin{aligned}
E\left(w_{g t} W_{g} t^{\prime}\right) & =W_{g t} & & \text { if } g=g^{\prime} \text { and } t=t^{\prime} \\
& =0 & & \text { else. }
\end{aligned}
$$

The $(k, 1)$-coefficient of the covariance matrix $W_{g t}$ can be proven to be $w_{g t}{ }^{k l}=1 / N_{g t}\left(d_{k 1}\left(1 / p_{t}(i \mid g)+\left(1 / p_{t}(0 \mid g)\right)\right.\right.$

where

$\mathrm{N}_{\mathrm{gt}}=$ number of employed people within industry $\mathrm{g}$ at time $\mathrm{t}$ and

$d_{k 1}=1$ if $k=1$

$d_{k 1}=0$ else.

Then equation (11) equals

$y=x \beta+v \quad$ where $\quad v \sim N(0, v)$ 
Estimation of the Modified Multinomial Model consist of applying Generalized Least Squares to equation twice (C.4) in the following way:

(1) The coefficients of the $\mathrm{Wgt}_{\mathrm{g}}$ 's are estimated by replacing the theoretical probabilities $p_{t}(i \mid g)$ by the observed frequencies $f_{t}(i \mid g)$. Then the Standard Multinomial Logit estimator BSML is calculated as

$$
\beta_{S M L}=\left(X^{\top} \hat{W^{-1}} X\right)^{-1} X^{\top} \hat{W^{-1}} y
$$

where $\hat{W}$ represents the estimated covariance matrix of the measurement error. We define the SML-residuals as

$u=y-x \beta_{S M L}$

$u=\left(u_{12}, u_{22} \ldots u_{G T}\right)^{\top}, u_{g t}=\left(u_{1 g t}, u_{2 g t} \ldots u_{I g t}\right)^{\top}$

(2) The SML-residuals are used to estimate the elements of covariance matrix $\Sigma$. We calculate :

$$
v^{k 1}=1 / R^{k 1} \quad \sum_{t=2}^{T} \underset{g=1}{G} u_{k g t} u_{1 g t}
$$

Here only branches in which the labour category $i$ exists are taken into account, so that $\mathrm{R}^{\mathrm{k} l}$ equals the number of block-matrices within equation (C.1) that contain both categories of labour $k$ and 1.

(3) A consistent estimate of covariance matrix $\Sigma$, denoted as $\hat{\Sigma}$ with elements $e^{k 1}$, is then found by

$$
e^{k 1}=v^{k 1}-\left(1 / R^{k 1}\right) \sum_{t=2}^{T} \sum_{g=1}^{G} w_{g t}
$$

This estimated matrix $\hat{\Sigma}$, that should be semi-positive definite, is added to the estimated covariance matrices $\hat{W}_{g t}$ in ( $c .1$ ), so a new (positive definite) estimator of $V, \hat{v}$, is found.

(4) Finally the Modified Multinomial Logit estimator, $\beta_{M M L}$, is calculated by

$$
\beta_{M M L}=\left(X^{\prime} \hat{v}^{-1} X\right)^{-1} \quad X^{\prime} \hat{v}^{-1} y
$$


If only the measurement error is taken into account and the specification error should not be neglected (that is $\Sigma$ does not equal zero), the standard errors of the estimates will be biased downward. This follows from the fact that:

$$
\operatorname{Var}\left(\beta_{\mathrm{SML}}\right)=\left(\mathrm{X}^{\prime} \mathrm{W}^{-1} \mathrm{X}\right)^{-1} \mathrm{X}^{\prime} \mathrm{W}^{-1} \mathrm{VW}^{-1} \mathrm{X}\left(\mathrm{X}^{\prime} \mathrm{W}^{-1} \mathrm{X}\right)^{-1}>\operatorname{Var}\left(\beta_{\mathrm{MML}}\right)=\left(\mathrm{X}^{\prime} \mathrm{W}^{-1} \mathrm{X}\right)^{-1}
$$

We estimated the occupational and educational model by executing the first step, that is calculating $\beta_{S M L}$. We did however not succeed in calculating a semi-positive definite matrix $\Sigma$ (see C.7). This problem arose because of the fact that not every category of labour occurs within every branch (so the number of existing categories within branches, $\mathrm{R}^{\mathrm{k}}$, did not equal the maximum number of branches and points in time, being (T-1) $x$ G). For this reason we assumed $\Sigma$ within (C.2) to be diagonal instead of full-symmetric when estimating the occupational and educational models that distinguish 83 occupations and 58 educations. 
ANNEX D: The estimation results of the Multinomial Logit Method

ANNEX D.1 The occupational model

STANDARD MULTINOMIAL LOGIT

B $\quad$ SD

\begin{tabular}{|c|c|c|}
\hline LENDO & 0.842 & 0.0003 \\
\hline INVVA1 & -0.0265 & 0.0322 \\
\hline INVVA2 & -0.8156 & 0.0147 \\
\hline INVVA3 & 0.3276 & 0.0347 \\
\hline INVVA4 & -1.0818 & 0.0331 \\
\hline INVVA5 & -1.4304 & 0.0307 \\
\hline INVVA6 & -0.7408 & 0.0265 \\
\hline INVVA7 & 0.2478 & 0.044 \\
\hline INVVA8 & -2.1216 & 0.0684 \\
\hline INVVA9 & -0.7175 & 0.0342 \\
\hline INVVA10 & 1.3897 & 0.0264 \\
\hline INVVA11 & -1.0369 & 0.172 \\
\hline INVVA12 & -0.8346 & 0.0486 \\
\hline INVVA13 & -0.6521 & 0.0582 \\
\hline INVVA14 & -2.5881 & 0.1092 \\
\hline INVVA15 & -2.6425 & 0.1255 \\
\hline INVVA16 & -0.282 & 0.0184 \\
\hline INVVA17 & -5.311 & 0.1777 \\
\hline INVVA18 & -0.897 & 0.0196 \\
\hline INVVA19 & -1.2326 & 0.0414 \\
\hline INVVA20 & 2.6357 & 0.0782 \\
\hline INVVA21 & -0.496 & 0.0167 \\
\hline INVVA22 & -0.7831 & 0.0134 \\
\hline INVVA23 & 0.2413 & 0.0522 \\
\hline INVVA24 & -0.0623 & 0.0305 \\
\hline INVVA25 & -1.8862 & 0.337 \\
\hline INVVA26 & 0.5833 & 0.0414 \\
\hline INVVA27 & -0.2647 & 0.0428 \\
\hline INVVA29 & 9.4235 & 1.4708 \\
\hline INVVA30 & 3.913 & 0.3324 \\
\hline INVVA31 & 35.9036 & 1.5182 \\
\hline INVVA32 & 33.5713 & 1.3097 \\
\hline INVVA33 & -1.703 & 0.051 \\
\hline INVVA34 & -1.2298 & 0.0642 \\
\hline INVVA35 & -1.2265 & 0.052 \\
\hline INVVA36 & -0.852 & 0.0477 \\
\hline INVVA37 & 9.919 & 0.3101 \\
\hline INVVA38 & -0.1412 & 0.0534 \\
\hline INVVA39 & 26.1123 & 0.7973 \\
\hline INVVA40 & 2.0384 & 0.0678 \\
\hline INVVA41 & -1.73 & 0.0236 \\
\hline INVVA42 & -0.8693 & 0.0301 \\
\hline INVVA43 & -0.4944 & 0.0195 \\
\hline INVVA44 & 0.6156 & 0.2552 \\
\hline INVVA45 & 3.1519 & 0.2706 \\
\hline INVVA46 & 0.3869 & 0.0267 \\
\hline INVVA47 & -2.0438 & 0.0461 \\
\hline INVVA48 & 2.5412 & 0.182 \\
\hline
\end{tabular}

MODIFIED MULTINOMIAL LOGIT (-)

B SD

\begin{tabular}{|c|c|c|}
\hline 0 & & \\
\hline INVVA1 & -0.8097 & 2444 \\
\hline VVA2 & 0.0562 & .4337 \\
\hline VVA3 & 1.0428 & 2.282 \\
\hline VVA4 & -3.2783 & 2.1963 \\
\hline VVA5 & -1.239 & 1.5044 \\
\hline VVA6 & -0.1659 & 0.7416 \\
\hline IVVA7 & 1.4533 & 1.1773 \\
\hline IVVA8 & -1.0967 & 1.8183 \\
\hline IVVA9 & 0.2559 & 7266 \\
\hline IVVA10 & 0.5719 & 1.3149 \\
\hline [NVVA11 & -4.8894 & 884 \\
\hline NVVA12 & 0.2525 & 1.1675 \\
\hline IVVA13 & -1.3342 & \\
\hline IVVA14 & -3 & 3.0522 \\
\hline IVVA15 & -1.7 & 598 \\
\hline NVVA16 & -0.5 & \\
\hline NVVA17 & -0 & 88 \\
\hline INVVA18 & -0 . & \\
\hline INVVA19 & -0.4376 & \\
\hline INVVA20 & 3.1265 & \\
\hline INVVA21 & -0.6205 & 56 \\
\hline INVVA22 & -0.1304 & \\
\hline NVVA23 & -0.5325 & 293 \\
\hline JVVA24 & 1.1035 & \\
\hline NVVA25 & 1.2494 & 06 \\
\hline JVVA26 & 1.0166 & \\
\hline IVVA27 & 0.2116 & 329 \\
\hline IVVA29 & 9.6503 & 39 \\
\hline IVVA30 & 2.9322 & \\
\hline JVVA31 & 29.6085 & 993 \\
\hline IVVA32 & 73. & 15. \\
\hline INVVA33 & -1.2413 & \\
\hline INVVA34 & -2.5272 & \\
\hline INVVA35 & -1.6232 & 905 \\
\hline INVVA36 & -2.6165 & \\
\hline INVVA37 & 6.8501 & 375 \\
\hline INVVA38 & -0.2502 & 1.681 \\
\hline INVVA39 & 17.8255 & 3.2483 \\
\hline INVVA40 & 2.7978 & 1.7719 \\
\hline INVVA41 & -0.4923 & 0.6915 \\
\hline INVVA42 & 0.1141 & 1.5004 \\
\hline INVVA43 & -1.5539 & 0.882 \\
\hline INVVA44 & 3.4266 & 2.9359 \\
\hline INVVA45 & -4.2828 & 3.2031 \\
\hline INVVA46 & 0.8569 & 0.9624 \\
\hline INVVA47 & -0.7808 & 1.1304 \\
\hline INVVA48 & 2.0986 & 2.5891 \\
\hline
\end{tabular}




$\begin{array}{lcl}\text { INVVA49 } & -0.4781 & 0.5217 \\ \text { INVVA50 } & 2.555 & 0.0528 \\ \text { INVVA51 } & 3.9102 & 0.1739 \\ \text { INVVA52 } & 2.6466 & 0.4335 \\ \text { INVVA53 } & -0.1333 & 0.0243 \\ \text { INVVA54 } & 3.3606 & 0.3014 \\ \text { INVVA55 } & 7.055 & 0.1311 \\ \text { INVVA56 } & 10.4599 & 0.2929 \\ \text { INVVA57 } & 2.8877 & 0.0779 \\ \text { INVVA58 } & -1.9462 & 0.1521 \\ \text { INVVA59 } & 12.4823 & 1.2026 \\ \text { INVVA60 } & 4.2207 & 0.0737 \\ \text { INVVA61 } & -2.4368 & 5.2452 \\ \text { INVVA62 } & -0.383 & 0.0935 \\ \text { INVVA63 } & 6.406 & 0.2213 \\ \text { INVVA64 } & 5.7323 & 0.1609 \\ \text { INVVA65 } & -48.901 & 1.5335 \\ \text { INVVA66 } & -2.4302 & 0.073 \\ \text { INVVA67 } & -0.469 & 0.0183 \\ \text { INVVA68 } & -0.3314 & 0.0196 \\ \text { INVVA69 } & -0.0404 & 0.1966 \\ \text { INVVA70 } & -0.9927 & 0.0241 \\ \text { INVVA71 } & -13.6103 & 0.7842 \\ \text { INVVA72 } & 0.8562 & 0.187 \\ \text { INVVA73 } & 1.629 & 0.1201 \\ \text { INVVA74 } & 8.6694 & 0.6589 \\ \text { INVVA75 } & 0.0887 & 0.0576 \\ \text { INVVA76 } & -0.6976 & 0.0673 \\ \text { INVVA77 } & 0.2099 & 0.0897 \\ \text { INVVA78 } & -1.8915 & 0.031 \\ \text { INVVA79 } & 0.6084 & 0.0463 \\ \text { INVVA80 } & 0.0148 & 0.0176 \\ \text { INVVA81 } & 0.2852 & 0.0188 \\ \text { INVVA82 } & -1.4919 & 0.0379 \\ \text { INVVA83 } & -6.7962 & 0.1701 \\ \text { DCU1 } & -0.2717 & 0.006 \\ \text { DCU2 } & 0.0081 & 0.0025 \\ \text { DCU3 } & -0.226 & 0.0127 \\ \text { DCU4 } & -0.0231 & 0.0055 \\ \text { DCU5 } & 0.3546 & 0.0029 \\ \text { DCU6 } & -0.04 & 0.0041 \\ \text { DCU7 } & -0.3064 & 0.0071 \\ \text { DCU8 } & -0.0806 & 0.0059 \\ \text { DCU9 } & -0.0284 & 0.0068 \\ \text { DCU10 } & -0.2516 & 0.0074 \\ \text { DCU11 } & -0.0938 & 0.0105 \\ \text { DCU12 } & -0.086 & 0.007 \\ \text { DCU13 } & -0.2021 & 0.0052 \\ \text { DCU14 } & -0.0491 & 0.0084 \\ \text { DCU15 } & -0.1308 & 0.0101 \\ \text { DCU16 } & -0.0188 & 0.0034 \\ \text { DCU17 } & 1.0948 & 0.0518 \\ \text { DCU18 } & 0.0633 & 0.0027 \\ \text { DCU19 } & -0.0033 & 0.0092 \\ \text { DCU20 } & -1.0352 & 0.0228 \\ \text { DCU21 } & -0.0712 & 0.0028 \\ \text { DCU22 } & 0.0819 & 0.0023 \\ \text { DCU23 } & -0.3944 & 0.0077\end{array}$

$\begin{array}{lcc}\text { INVVA49 } & 21.3501 & 10.4462 \\ \text { INVVA50 } & -3.0422 & 1.4484 \\ \text { INVVA51 } & 3.4215 & 2.7343 \\ \text { INVVA52 } & 6.1385 & 2.9789 \\ \text { INVVA53 } & -0.4552 & 0.8705 \\ \text { INVVA54 } & 0.3748 & 2.6952 \\ \text { INVVA55 } & 3.6639 & 2.5154 \\ \text { INVVA56 } & -0.3079 & 5.0684 \\ \text { INVVA57 } & 2.8948 & 1.7075 \\ \text { INVVA58 } & 6.31 & 6.1789 \\ \text { INVVA59 } & 1.0015 & 11.5782 \\ \text { INVVA60 } & -0.9076 & 2.9064 \\ \text { INVVA61 } & -20.7115 & 39.9821 \\ \text { INVVA62 } & -2.1695 & 1.4154 \\ \text { INVVA63 } & 0.2363 & 4.8112 \\ \text { INVVA64 } & -0.8599 & 2.7598 \\ \text { INVVA65 } & -12.7561 & 10.315 \\ \text { INVVA66 } & -1.5473 & 1.5163 \\ \text { INVVA67 } & 0.1008 & 0.4746 \\ \text { INVVA68 } & 0.7914 & 0.9501 \\ \text { INVVA69 } & -5.3298 & 2.8211 \\ \text { INVVA70 } & 0.0626 & 0.9992 \\ \text { INVVA71 } & 6.1219 & 12.6805 \\ \text { INVVA72 } & -0.9145 & 2.7914 \\ \text { INVVA73 } & 7.1689 & 3.033 \\ \text { INVVA74 } & -0.1934 & 6.9717 \\ \text { INVVA75 } & 0.3925 & 1.1217 \\ \text { INVVA76 } & -2.5677 & 1.6546 \\ \text { INVVA77 } & -1.3432 & 1.71 \\ \text { INVVA78 } & -0.4594 & 0.8172 \\ \text { INVVA79 } & 1.1517 & 1.2215 \\ \text { INVVA80 } & 0.5579 & 0.6916 \\ \text { INVVA81 } & 0.2371 & 1.1191 \\ \text { INVVA82 } & -1.4081 & 0.9793 \\ \text { INVVA83 } & -0.7438 & 2.5361 \\ \text { DCU1 } & -0.7653 & 0.2023 \\ \text { DCU2 } & -0.2752 & 0.0782 \\ \text { DCU3 } & -0.9219 & 0.4675 \\ \text { DCU4 } & -0.438 & 0.3388 \\ \text { DCU5 } & -0.8436 & 0.283 \\ \text { DCU6 } & -0.6796 & 0.1355 \\ \text { DCU7 } & -1.2337 & 0.2177 \\ \text { DCU8 } & -1.2454 & 0.337 \\ \text { DCU9 } & -1.1167 & 0.3374 \\ \text { DCU10 } & -1.1215 & 0.2474 \\ \text { DCU11 } & -0.8154 & 0.4629 \\ \text { DCU12 } & -1.2437 & 0.2074 \\ \text { DCU13 } & -0.6431 & 0.2868 \\ \text { DCU14 } & -1.0336 & 0.434 \\ \text { DCU15 } & -1.5365 & 0.4596 \\ \text { DCU16 } & -0.8999 & 0.1618 \\ \text { DCU17 } & -1.0877 & 0.6933 \\ \text { DCU18 } & -0.0511 & 0.0704 \\ \text { DCU19 } & -1.1162 & 0.3342 \\ \text { DCU20 } & -2.0438 & 0.4966 \\ \text { DCU21 } & -0.2839 & 0.1484 \\ \text { DCU22 } & -0.1851 & 0.0743 \\ \text { DCU23 } & -0.9921 & 0.2441\end{array}$




\begin{tabular}{|c|c|c|c|c|c|}
\hline DCU24 & -0.1891 & 0.0073 & DCU24 & -1.045 & 0.2112 \\
\hline DCU25 & -0.0034 & 0.0761 & DCU25 & -1.2104 & 0.752 \\
\hline DCU26 & -0.2212 & 0.0092 & DCU26 & -1.1525 & 0.2443 \\
\hline DCU27 & -0.38 & 0.0079 & DCU27 & -1.201 & 0.1556 \\
\hline DCU29 & -0.3714 & 0.0847 & DCU29 & -1.04 & 1.5127 \\
\hline DCU30 & -0.2478 & 0.02 & DCU30 & -1.0024 & 0.691 \\
\hline DCU31 & -2.0807 & 0.088 & DCU31 & -2.3376 & 1.1297 \\
\hline DCU32 & -1.7881 & 0.0758 & DCU32 & -3.9412 & 0.6989 \\
\hline DCU33 & 0.0146 & 0.0052 & DCU33 & -0.7828 & 0.1904 \\
\hline DCU34 & 0.0396 & 0.0059 & DCU34 & -0.4916 & 0.2645 \\
\hline DCU35 & -0.0526 & 0.0044 & DCU35 & -0.9882 & 0.2697 \\
\hline DCU36 & 0.2749 & 0.0039 & DCU36 & -0.3342 & 0.2591 \\
\hline DCU37 & -1.224 & 0.0292 & DCU37 & -1.9824 & 0.5169 \\
\hline DCU38 & -0.3117 & 0.0066 & DCU38 & -0.9952 & 0.3149 \\
\hline DCU39 & -0.2604 & 0.0089 & DCU39 & -0.3644 & 0.1994 \\
\hline DCU40 & -0.3019 & 0.0077 & DCU40 & -1.5755 & 0.3207 \\
\hline DCU41 & 0.0105 & 0.0029 & DCU41 & -0.8276 & 0.1259 \\
\hline DCU42 & 0.1371 & 0.0031 & DCU42 & -1.1153 & 0.2744 \\
\hline $\mathrm{DCU} 43$ & 0.0156 & 0.0035 & DCU43 & -0.7089 & 0.1606 \\
\hline DCU44 & -0.2242 & 0.008 & DCU44 & -1.3782 & 0.3831 \\
\hline DCU45 & -0.0815 & 0.0053 & DCU45 & -0.5905 & 0.4347 \\
\hline DCU46 & -0.2018 & 0.0071 & DCU46 & -1.087 & 0.1793 \\
\hline DCU47 & -0.1192 & 0.005 & DCU47 & -1.2131 & 0.2111 \\
\hline DCU48 & -0.3959 & 0.0225 & DCU48 & -1.5257 & 0.4013 \\
\hline DCU49 & 0.3039 & 0.0669 & DCU49 & -1.2752 & 0.9516 \\
\hline DCU50 & -0.1881 & 0.0061 & DCU50 & -0.4504 & 0.2855 \\
\hline DCU51 & -0.6985 & 0.0213 & DCU51 & -1.3867 & 0.4536 \\
\hline DCU52 & -0.5171 & 0.0556 & DCU52 & -2.1505 & 0.4579 \\
\hline DCU53 & -0.0684 & 0.0035 & DCU53 & -0.4056 & 0.158 \\
\hline DCU54 & -0.4833 & 0.0221 & DCU54 & -1.2892 & 0.4253 \\
\hline DCU55 & -0.89 & 0.0151 & DCu55 & -1.2645 & 0.4278 \\
\hline DCU56 & -1.2501 & 0.0291 & DCU56 & -0.7296 & 0.7065 \\
\hline DCU57 & -0.5114 & 0.0136 & DCU57 & -1.4327 & 0.2903 \\
\hline DCU58 & -0.0168 & 0.0148 & DCU58 & -1.6009 & 0.6064 \\
\hline DCU59 & -1.1201 & 0.0867 & DCU59 & -0.9096 & 1.1719 \\
\hline DCU60 & -0.3919 & 0.0093 & DCU60 & -1.1238 & 0.4851 \\
\hline DCU61 & 0.0291 & 0.7377 & DCU61 & 2.3856 & 5.6157 \\
\hline DCU62 & -0.1067 & 0.0082 & DCU62 & -0.7905 & 0.2464 \\
\hline DCU63 & -0.5566 & 0.0144 & DCU63 & -1.1415 & 0.522 \\
\hline DCU64 & -0.7491 & 0.0159 & DCU64 & -0.9451 & 0.4024 \\
\hline DCU65 & 5.034 & 0.1645 & DCU65 & 1.0335 & 0.9108 \\
\hline DCU66 & 0.0962 & 0.0068 & DCU66 & -0.745 & 0.2859 \\
\hline DCU67 & -0.0187 & 0.0026 & DCU67 & -0.3121 & 0.0853 \\
\hline DCU68 & -0.011 & 0.0032 & DCU68 & -0.4602 & 0.1722 \\
\hline DCU69 & -0.0982 & 0.0204 & DCU69 & -0.8486 & 0.4104 \\
\hline DCU70 & 0.032 & 0.0031 & DCU70 & -0.7762 & 0.1851 \\
\hline DCU71 & 0.6525 & 0.0515 & DCU71 & -1.8384 & 0.9115 \\
\hline DCU72 & -0.2438 & 0.0212 & DCU72 & -1.0654 & 0.461 \\
\hline DCU73 & -0.3686 & 0.0206 & DCU73 & -1.7892 & 0.4191 \\
\hline DCU74 & -0.9169 & 0.065 & DCU74 & -1.012 & 0.7707 \\
\hline DCU75 & -0.0339 & 0.0068 & DCU75 & -1.2022 & 0.2024 \\
\hline DCU76 & -0.0691 & 0.0049 & DCU76 & -0.5779 & 0.2944 \\
\hline DCU77 & -0.3387 & 0.011 & DCU77 & -0.788 & 0.2966 \\
\hline DCU78 & 0.2339 & 0.003 & DCU78 & -0.6948 & 0.1492 \\
\hline DCU79 & -0.479 & 0.0123 & DCU79 & -1.6431 & 0.2291 \\
\hline DCU80 & -0.0181 & 0.0029 & DCU83O & -0.3486 & 0.1244 \\
\hline DCU81 & -0.0523 & 0.0038 & DCU81 & -0.4755 & 0.2018 \\
\hline DCU82 & -0.0482 & 0.0041 & DCU82 & -0.92 & 0.1791 \\
\hline DCU83 & 1.9016 & 0.0507 & DCU83 & -0.2248 & 0.4267 \\
\hline
\end{tabular}


$R^{2}-A D J=0.9428$

$R^{2}-A D J=0.8261$

Number of observations $=3260$

Reference category is occupation 28 "clerical and related workers". 
D.2. The educational model

STANDARD MULTINOMIAL LOGIT

B $\quad$ SD

\begin{tabular}{|c|c|c|}
\hline LENDO & 0.5386 & 然 \\
\hline INVVA2 & 0.6642 & 0.012 \\
\hline INVVA3 & 1.5729 & 0.036 \\
\hline NVVA4 & -0.8705 & 0.012 \\
\hline JVVA5 & -0.453 & 0.037 \\
\hline IVVA6 & 0.1801 & 0.186 \\
\hline IVVA7 & -0.3927 & 0.020 \\
\hline IVVA8 & -1.6414 & 0.020 \\
\hline IVVA9 & -2.4945 & 0.080 \\
\hline IVVA10 & -0.3432 & 0.059 \\
\hline IVVA12 & 4.8269 & 0.031 \\
\hline IVVA13 & 1.5591 & \\
\hline IVVA14 & -0.4122 & 0.012 \\
\hline IVVA15 & 0.661 & \\
\hline IVVA16 & -4.874 & 0.042 \\
\hline IVVA17 & 97 & \\
\hline IVVA18 & -4.132 & 0.092 \\
\hline IVVA19 & -1 & 0.012 \\
\hline IVVA20 & 3.5038 & 0.032 \\
\hline IVVA21 & 23 & \\
\hline IVVA22 & -2.2403 & \\
\hline IVVA23 & -3 & \\
\hline IVVA24 & 447 & 0.032 \\
\hline IVVA25 & 0. & \\
\hline IVVA26 & 6. & 0 . \\
\hline IVVA27 & -3. & \\
\hline IVVA28 & -7 & \\
\hline NVVA29 & & \\
\hline IVVA30 & & \\
\hline & & \\
\hline JVVA32 & & \\
\hline & & \\
\hline IVVA34 & & 0 . \\
\hline & & \\
\hline JVVA36 & & \\
\hline IVVA37 & 1.7 & 0 . \\
\hline JVVA38 & 1. & 0 . \\
\hline INVVA39 & -0. & 0 . \\
\hline INVVA40 & 0. & \\
\hline INVVA41 & -2.3 & 0 . \\
\hline IVVA42 & 72 & 0 . \\
\hline INVVA43 & 0.2722 & \\
\hline INVVA44 & 2.238 & \\
\hline INVVA45 & 1. & 0 . \\
\hline INVVA46 & -5.4062 & 0.091 \\
\hline INVVA47 & -1 & 0 . \\
\hline INVVA48 & 0.3822 & 0.038 \\
\hline INVVA49 & -0.7206 & 0.03 \\
\hline INVVA50 & -1.6324 & 0.046 \\
\hline INVVA51 & 2.1848 & 0.1 \\
\hline INVVA52 & -0.0762 & 0.037 \\
\hline INVVA5: & -0.4552 & 0.105 \\
\hline
\end{tabular}

MODIFIED MULTINOMIAL LOGIT (-)

B $\quad$ SD

$\begin{array}{lll}\text { LENDO } & 0.4065 & 0.0158 \\ \text { INVVA2 } & 0.9864 & 1.4998 \\ \text { INVVA3 } & 1.371 & 2.6847 \\ \text { INVVA4 } & 1.0343 & 1.5254 \\ \text { INVVA5 } & 1.2931 & 3.5655 \\ \text { INVVA6 } & 2.9731 & 8.323 \\ \text { INVVA7 } & 1.4261 & 1.9013 \\ \text { INVVA8 } & 0.0488 & 2.3493\end{array}$

INVVA9 $\quad-0.615 \quad 8.5514$

$\begin{array}{lll}\text { INVVA10 } & 1.719 \quad 3.4887\end{array}$

INVVA12 $3.137 \quad 3.3652$

$\begin{array}{lll}\text { INVVA13 } & 0.9097 & 2.7089\end{array}$

INVVA14 $1.0701 \quad 1.4889$

INVVA15 $\quad 2.0689 \quad 2.0251$

INVVA16 $1.3537 \quad 3.8016$

INVVA17 $1.1191 \quad 4.4004$

INVVA18 $-1.1734 \quad 6.159$

INVVA19 $0.7533 \quad 1.6253$

INVVA20 $2.4526 \quad 3.6983$

INVVA21 $1.7642 \quad 3.1824$

$\begin{array}{lll}\text { INVVA22 } & 0.7291 & 2.5567\end{array}$

INVVA23 $-0.0356 \quad 3.6723$

$\begin{array}{lll}\text { INVVA24 } & 2.6087 & 2.6929\end{array}$

INVVA25 $\quad 1.8642 \quad 3.4538$

$\begin{array}{lll}\text { INVVA26 } & 0.538 & 2.1046\end{array}$

INVVA27 $1.5126 \quad 5.6288$

$\begin{array}{lll}\text { INVVA28 } & -0.31 \quad 14.558\end{array}$

INVVA29 $\quad 0.5675 \quad 4.7609$

INVVA30 $\quad 2.3551 \quad 3.5439$

$\begin{array}{lll}\text { INVVA31 } & 0.7621 & 2.367\end{array}$

INVVA32 $1.4021 \quad 3.2943$

INVVA33 $1.0926 \quad 6.6215$

$\begin{array}{lll}\text { INVVA34 } & 0.2051 \quad 6.4298\end{array}$

$\begin{array}{lll}\text { INVVA35 } & 4.8136 \quad 7.8814\end{array}$

$\begin{array}{lll}\text { INVVA36 } & 0.4417 & 2.4231\end{array}$

INVVA37 $3.2927 \quad 6.9108$

$\begin{array}{lll}\text { INVVA38 } & 2.0645 \quad 4.287\end{array}$

INVVA39 $\quad 1.5359 \quad 3.6597$

INVVA40 $2.1523 \quad 5.2722$

INVVA41 $2.8667 \quad 5.2126$

$\begin{array}{lll}\text { INVVA42 } & 0.0715 & 6.6871\end{array}$

INVVA43 $1.1714 \quad 3.8342$

INVVA44 $3.5322 \quad 6.4316$

INVVA45 $3.0742 \quad 4.8356$

INVVA46 $\quad 4.2265 \quad 6.1451$

$\begin{array}{lll}\text { INVVA47 } & 0.6433 & 7.4898\end{array}$

INVVA48 $\quad 1.4604 \quad 4.6145$

INVVA49 $-0.4766 \quad 3.5643$

INVVA50 $\quad 1.1359 \quad 5.5274$

INVVA51 $3.264 \quad 9.0841$

INVVA52 $\quad 0.8608 \quad 3.2901$

$\begin{array}{lll}\text { INVVA53 } & 2.0227 \quad 4.967\end{array}$ 


\begin{tabular}{|c|c|c|c|c|c|}
\hline INVVA54 & 0.7809 & 0.0408 & INVVA54 & 1.8422 & 3.9097 \\
\hline INVVA55 & -0.6595 & 0.0308 & INVVA55 & 0.9142 & 3.4169 \\
\hline INVVA56 & -2.7476 & 0.1324 & INVVA56 & 4.0606 & 10.4713 \\
\hline INVVA57 & -2.3476 & 0.537 & INVVA57 & -2.3471 & 10.896 \\
\hline INVVA58 & -1.2086 & 0.0912 & INVVA58 & 3.2647 & 6.529 \\
\hline DCU2 & -0.1014 & 0.0062 & DCU2. & 0.3553 & 0.374 \\
\hline DCU3 & 1.3471 & 0.0645 & DCU3 & 2.6513 & 3.2816 \\
\hline DCU4 & 0.3251 & 0.0086 & DCU4 & 0.6719 & 0.4826 \\
\hline DCU5 & 0.296 & 0.0297 & DCU5 & -0.2935 & 1.59 \\
\hline DCU6 & 1.8537 & 0.1516 & DCU6 & -0.7155 & 3.814 \\
\hline DCU7 & 1.6467 & 0.0255 & DCU7 & 0.9565 & 1.1301 \\
\hline DCU8 & 0.4832 & 0.0169 & DCU8 & 0.7263 & 0.9878 \\
\hline DCU9 & 0.6328 & 0.0775 & DCU9 & 1.6443 & 4.1267 \\
\hline DCU10 & -0.4262 & 0.0082 & DCU10 & -1.0292 & 0.5529 \\
\hline DCU12 & 2.3514 & 0.0626 & DCU12 & 2.287 & 2.5533 \\
\hline DCU13 & 0.1694 & 0.039 & DCU13 & 4.2272 & 1.7897 \\
\hline DCU14 & 0.1979 & 0.0057 & DCU14 & 1.0766 & 0.371 \\
\hline DCU15 & -0.2896 & 0.0134 & DCU15 & 0.164 & 0.6988 \\
\hline DCU16 & 0.5828 & 0.0306 & DCU16 & 2.0394 & 1.7685 \\
\hline DCU17 & 0.0828 & 0.0439 & DCU17 & 1.3092 & 1.8882 \\
\hline DCU18 & -0.095 & 0.0677 & DCU18 & 0.3402 & 4.1215 \\
\hline DCU19 & 0.2374 & 0.0049 & DCU19 & 0.8903 & 0.346 \\
\hline DCU2O & -0.6919 & 0.0131 & DCU20 & 0.083 & 0.8851 \\
\hline DCU21 & 0.1081 & 0.0207 & DCU21 & 1.2079 & 1.078 \\
\hline DCU22 & 0.0428 & 0.0209 & DCU22 & 0.3744 & 1.3521 \\
\hline DCU23 & -0.1685 & 0.0425 & DCU23 & 0.4843 & 2.5004 \\
\hline DCU24 & 0.4806 & 0.0621 & DCU24 & 3.9315 & 2.7913 \\
\hline DCU25 & -0.8685 & 0.0087 & DCU25 & -0.8642 & 0.5511 \\
\hline DCU26 & -0.7187 & 0.0157 & DCU26 & 1.0771 & 0.6971 \\
\hline DCU27 & 1.3798 & 0.0825 & DCU27 & 2.255 & 3.4438 \\
\hline DCU28 & -1.7542 & 0.0955 & DCU28 & 3.4808 & 7.464 \\
\hline DCU29 & 3.6501 & 0.0782 & DCU29 & 6.1117 & 3.78 \\
\hline DCU30 & -0.1574 & 0.0462 & DCU30 & 3.5158 & 2.163 \\
\hline DCU31 & 0.4897 & 0.0144 & DCU31 & 1.8334 & 0.9938 \\
\hline DCU32 & -0.6063 & 0.029 & DCU32 & 0.9177 & 2.0734 \\
\hline DCU33 & 0.2402 & 0.0396 & DCU33 & 3.8057 & 3.8969 \\
\hline DCU34 & 1.2186 & 0.0454 & DCU34 & 2.6501 & 3.7615 \\
\hline DCU35 & 1.5856 & 0.1652 & DCU35 & -0.7499 & 7.4293 \\
\hline DCU36 & 0.0285 & 0.0156 & DCU36 & 1.8752 & 0.9582 \\
\hline DCU37 & 1.0435 & 0.0554 & DCU 37 & 2.0292 & 2.6811 \\
\hline DCU38 & -0.0059 & 0.0339 & DCU38 & 1.8337 & 1.9977 \\
\hline DCU39 & 0.8433 & 0.0226 & DCU39 & 2.9931 & 1.8233 \\
\hline DCU40 & 1.8773 & 0.0863 & DCU40 & -0.1914 & 3.8882 \\
\hline DCU41 & 2.0476 & 0.0822 & DCU41 & 5.078 & 3.7268 \\
\hline $\mathrm{DCU} 42$ & 2.3142 & 0.2229 & DCU42 & 5.48 & 11.7974 \\
\hline $\mathrm{DCU} 43$ & -0.6981 & 0.009 & DCU43 & -0.3629 & 0.6158 \\
\hline DCU44 & -0.1172 & 0.0516 & DCU44 & 0.3881 & 2.4012 \\
\hline DCU45 & 1.0786 & 0.103 & DCU45 & 2.8024 & 4.451 \\
\hline DCU46 & 0.2876 & 0.1172 & DCU46 & 4.9056 & 4.7473 \\
\hline DCU47 & 1.3444 & 0.1005 & DCU47 & 4.1496 & 5.923 \\
\hline $\mathrm{DCU} 48$ & 0.0778 & 0.0471 & DCU48 & 0.969 & 2.613 \\
\hline DCU49 & 0.6173 & 0.0298 & DCU49 & 2.0088 & 1.9617 \\
\hline DCU50 & -0.2759 & 0.0543 & DCU50 & 4.6367 & 3.5982 \\
\hline DCU51 & -0.3869 & 0.2686 & DCU51 & 5.1139 & 12.4337 \\
\hline DCU52 & 0.9375 & 0.0315 & DCU52 & 3.8556 & 1.7843 \\
\hline DCU53 & 1.9066 & 0.071 & DCU53 & 4.5196 & 2.8 \\
\hline DCU54 & 1.9554 & 0.0334 & DCU54 & 4.331 & 2.2066 \\
\hline DCU55 & 0.3974 & 0.0383 & DCU55 & 1.8149 & 1.8578 \\
\hline
\end{tabular}




\begin{tabular}{|c|c|c|c|c|c|}
\hline DCU56 & 1.4686 & 0.3157 & DCU56 & 2.3077 & 14.9514 \\
\hline DCU57 & -0.9256 & 1.6421 & DCU57 & -15.4902 & 62.8773 \\
\hline DCU58 & -0.0081 & 0.0207 & DCU58 & -0.2502 & 1.1241 \\
\hline PLF2 & 0.0849 & 0.006 & PLF2 & 0.2122 & 0.3162 \\
\hline PLF3 & 0.6335 & 0.0228 & PLF3 & 1.2533 & 1.1647 \\
\hline PLF4 & 0.267 & 0.0085 & PLF4 & 0.3858 & 0.4363 \\
\hline PLF5 & 0.2898 & 0.0299 & PLF5 & 0.6331 & 1.5081 \\
\hline PLF6 & 2.1955 & 0.1415 & PLF6 & 0.2439 & 3.4313 \\
\hline PLF7 & 0.8032 & 0.0097 & PLF7 & 0.555 & 0.4307 \\
\hline PLF8 & 0.4521 & 0.0153 & PLF8 & 0.8575 & 0.8609 \\
\hline PLF9 & 0.3359 & 0.079 & PLF9 & 1.7745 & 4.0651 \\
\hline PLF12 & 1.0145 & 0.0183 & PLF12 & 0.9867 & 0.7451 \\
\hline PLF13 & 0.1794 & 0.0129 & PLF13 & 1.6239 & 0.5986 \\
\hline PLF14 & 0.0874 & 0.0049 & PLF14 & 0.6678 & 0.2831 \\
\hline PLF15 & 0.1884 & 0.0106 & PLF15 & 0.8865 & 0.5212 \\
\hline PLF16 & 0.0755 & 0.0142 & PLF16 & 1.2562 & 0.8052 \\
\hline PLF17 & 0.3009 & 0.0204 & PLF17 & 0.8763 & 0.8849 \\
\hline PLF18 & -0.1622 & 0.0316 & PLF18 & 0.6346 & 1.8839 \\
\hline PLF19 & -0.0762 & 0.0044 & PLF19 & 0.6118 & 0.2638 \\
\hline PLF20 & 0.1866 & 0.0106 & PLF20 & 1.0045 & 0.6983 \\
\hline PLF21 & 0.3568 & 0.0114 & PLF21 & 1.0637 & 0.567 \\
\hline PLF22 & 0.0272 & 0.0115 & PLF22 & 0.45 & 0.7178 \\
\hline PLF23 & -0.1025 & 0.023 & PLF23 & 0.6696 & 1.3224 \\
\hline PLF24 & 0.4291 & 0.0177 & PLF24 & 1.3948 & 0.7925 \\
\hline PLF26 & 0.1025 & 0.008 & PLF26 & 0.7342 & 0.3471 \\
\hline PLF27 & 0.3972 & 0.0256 & PLF27 & 0.8291 & 1.0645 \\
\hline PLF28 & -0.8449 & 0.029 & PLF28 & 1.0196 & 2.3225 \\
\hline PLF29 & 0.8552 & 0.0146 & PLF29 & 1.2026 & 0.7122 \\
\hline PLF30 & 0.0502 & 0.0104 & PLF30 & 0.8713 & 0.4833 \\
\hline PLF31 & 0.1889 & 0.0051 & PLF31 & 0.6599 & 0.3581 \\
\hline PLF32 & 0.0903 & 0.0102 & PLF32 & 0.5016 & 0.7124 \\
\hline PLF33 & 0.0001 & 0.0118 & PLF33 & 1.2951 & 1.1646 \\
\hline PLF34 & 0.3816 & 0.0137 & PLF34 & 0.9015 & 1.1384 \\
\hline PLF35 & 0.7995 & 0.0475 & PLF35 & 0.046 & 2.1023 \\
\hline PLF36 & 0.0437 & 0.0052 & PLF36 & 0.5234 & 0.3329 \\
\hline PLF37 & 0.5108 & 0.0189 & PLF37 & 0.6748 & 0.9229 \\
\hline PLF38 & 0.2155 & 0.0114 & PLF38 & 0.7638 & 0.705 \\
\hline PLF39 & 0.2258 & 0.007 & PLF39 & 1.0279 & 0.5667 \\
\hline PLF40 & 0.675 & 0.0259 & PLF40 & 0.2048 & 1.1446 \\
\hline PLF41 & 0.4455 & 0.0197 & PLF41 & 1.3132 & 0.896 \\
\hline PLF42 & 0.4871 & 0.0399 & PLF42 & 1.0383 & 2.1117 \\
\hline PLF44 & 0.2517 & 0.0274 & PLF44 & 0.273 & 1.2538 \\
\hline PLF45 & 0.3586 & 0.0237 & PLF45 & 0.7244 & 1.0293 \\
\hline PLF46 & -0.0851 & 0.0273 & PLF46 & 1.1865 & 1.116 \\
\hline PLF47 & 0.3037 & 0.0174 & PLF47 & 0.688 & 1.0318 \\
\hline PLF48 & 0.0954 & 0.0111 & PLF48 & 0.1933 & 0.6239 \\
\hline PLF49 & 0.1969 & 0.0074 & PLF49 & 0.4169 & 0.5103 \\
\hline PLF50 & -0.1152 & 0.0139 & PLF50 & 1.1431 & 0.9595 \\
\hline PLF51 & 0.194 & 0.0678 & PLF51 & 1.3122 & 3.1854 \\
\hline PLF52 & 0.2843 & 0.0073 & PLF52 & 0.9062 & 0.4422 \\
\hline PLF53 & 0.4823 & 0.0169 & PLF53 & 1.0181 & 0.6891 \\
\hline PLF54 & 0.5868 & 0.008 & PLF54 & 1.0854 & 0.5585 \\
\hline PLF55 & 0.0453 & 0.0098 & PLF55 & 0.4246 & 0.4971 \\
\hline PLF56 & 0.4764 & 0.0761 & PLF56 & 0.7297 & 3.5913 \\
\hline PLF57 & -0.1921 & 0.4006 & PLF57 & -4.058 & 15.2909 \\
\hline
\end{tabular}


$\mathrm{R} 2-\mathrm{ADJ}=$

$$
\mathrm{R} 2-\mathrm{ADJ}=0.437
$$

Number of observations $=25169$

Reference categories are education 1 "elementary education" and education 11 "general secondary education, intermediate and higher levels" 
Table 2. Educational levels

Category Educational level

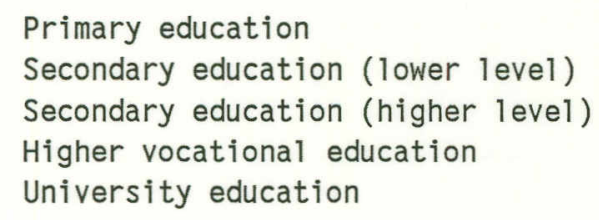

These categories of occupations and educations are mentioned in table 1 and 2 respectively. Employment shifts between these occupational categories from 1979 until 1985 are shown in figure I, where the seven numbers at the $x$-axis correspond to the seven categories mentioned in table 1. Obviously the monotonously increasing employment of the professional, technical and related workers (category 1 ) and the decline of the production and related workers (category 7 ) catch the eye.

Figure I. Working population within seven occupational categories during 1979-1985

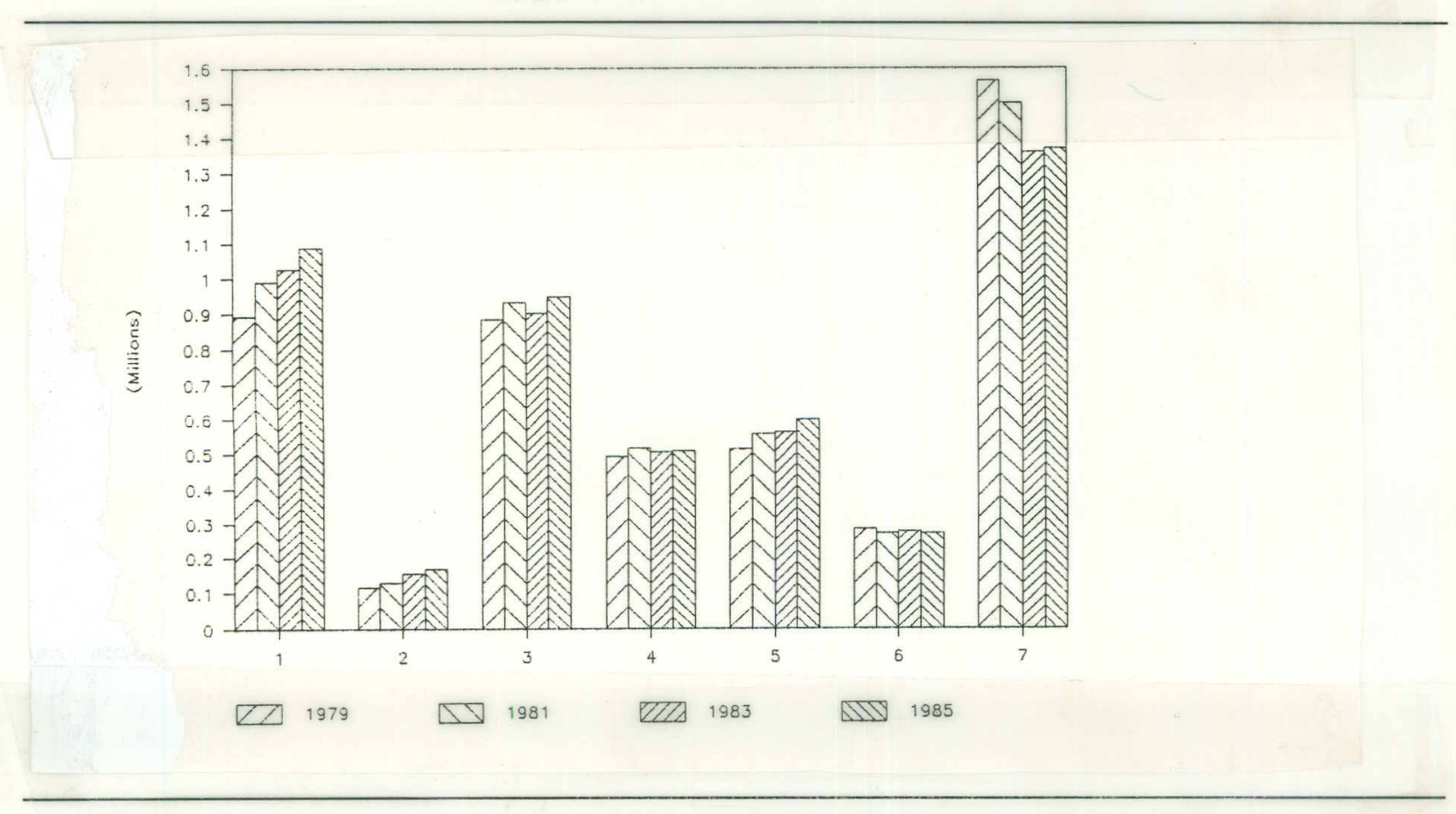

The figures IIa and IIb illustrate the educational background of the employed population in these seven categories in 1979 and 1985 . Because the seven categories are ranked from the highest to the lowest level occupations, it is not surprising that occupational category 1 contains relatively less persons with the lowest and more persons with the highest 
educational level than the other categories. Nevertheless, much more important here are the shifts in almost all occupations from the lower to the higher educational levels during 1979-1985.

Figure IIa. Educational background of persons employed within seven occupational categories in 1979

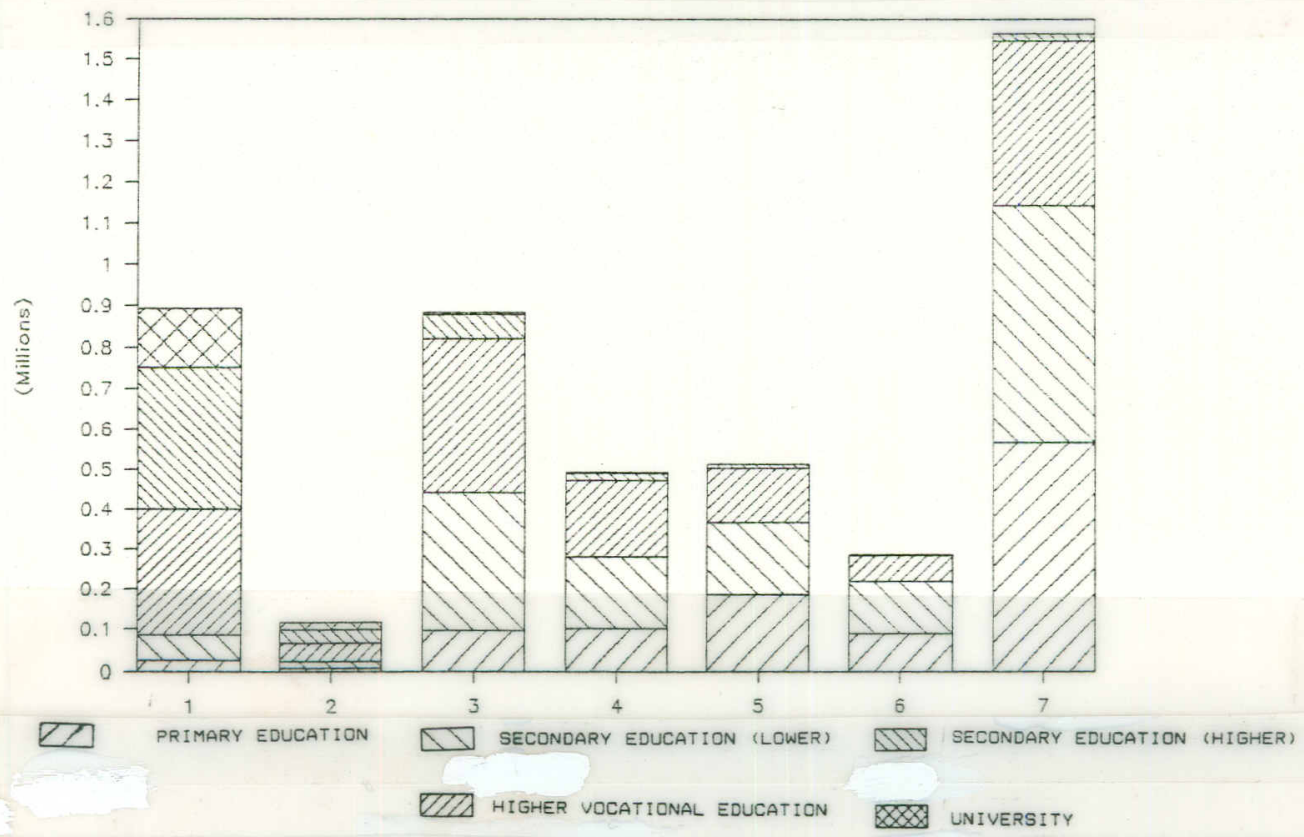

Figure IIb. Educational background of persons employed within seven occupational categories in 1985

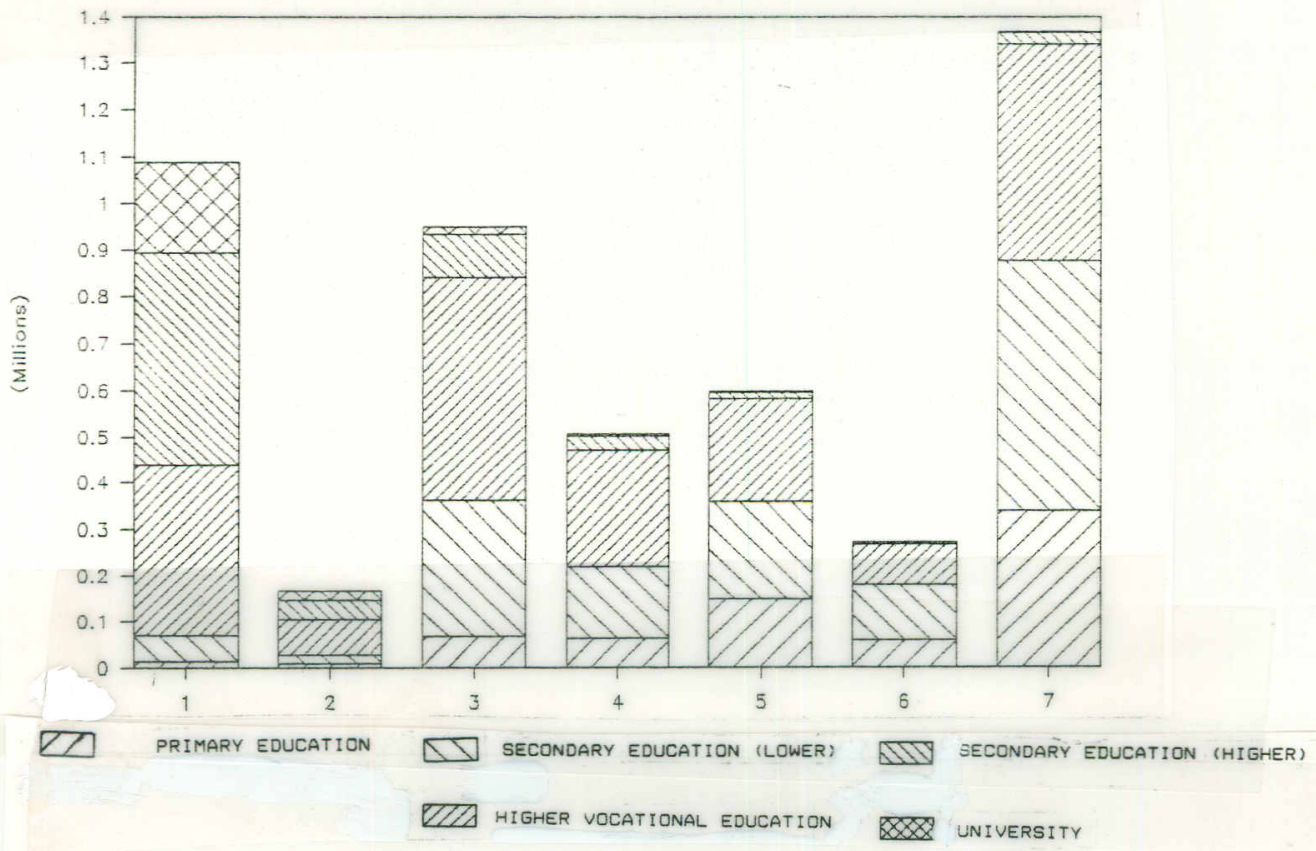


Figure IV. Employed persons and employed persons adjusted for the share of part-time work within three branches of industry in 1979 and 1985

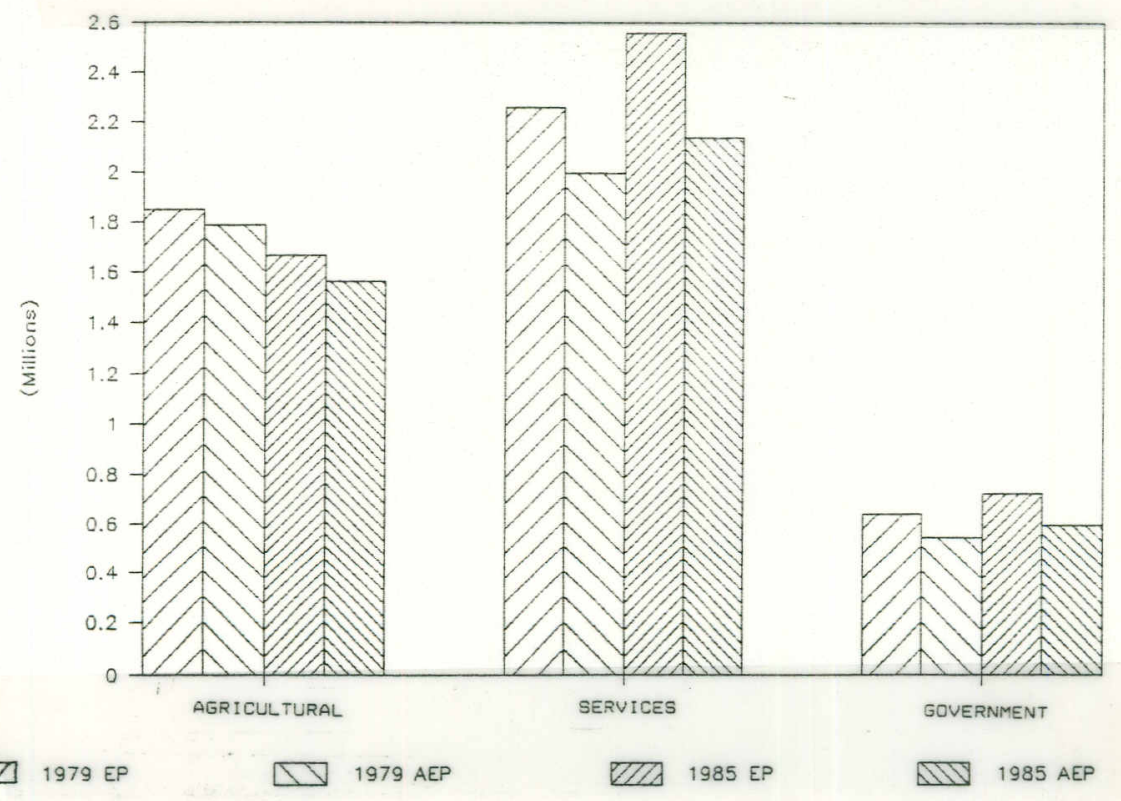

We assume that the adjustments for working hours of the number of employed persons with a certain educational background is fully determined by the occupation within a branch of industry they have. We therefore calculate the adjusted number of employed persons with certain educational backgrounds by multiplying those numbers with the average number of working hours of the occupation they have and industry they were working, so 2

$$
\operatorname{AEP}(b, 0, e, t):=\frac{\sum_{h} E P^{*}(b, o, h, t) * M H(h)}{\sum_{h} E P^{*}(b, o, h, t) * 40} * E P(b, o, e, t)
$$

with

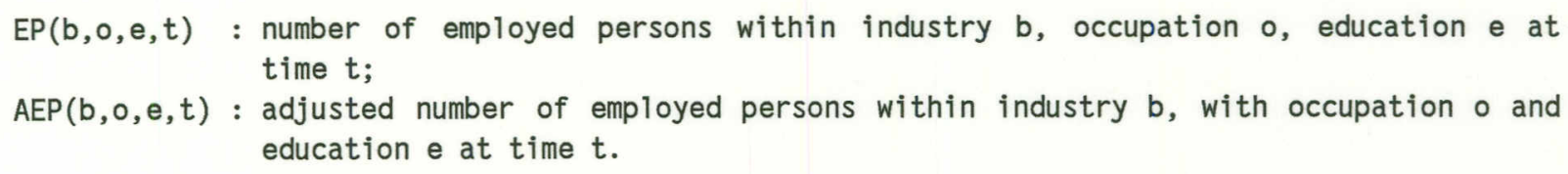

2. For the estimation method we use in chapter 3 there is no difference between taking account of the employed people or the adjusted employed people when calculating the endogenous variable of the educational model. This is because of the fact that nominator and denominator are adjusted by the same factor. Only the estimated covariance matrix is touched by the adjustments made here for part-time work. 
Figure IV. Employed persons and employed persons adjusted for the share of part-time work within three branches of industry in 1979 and 1985

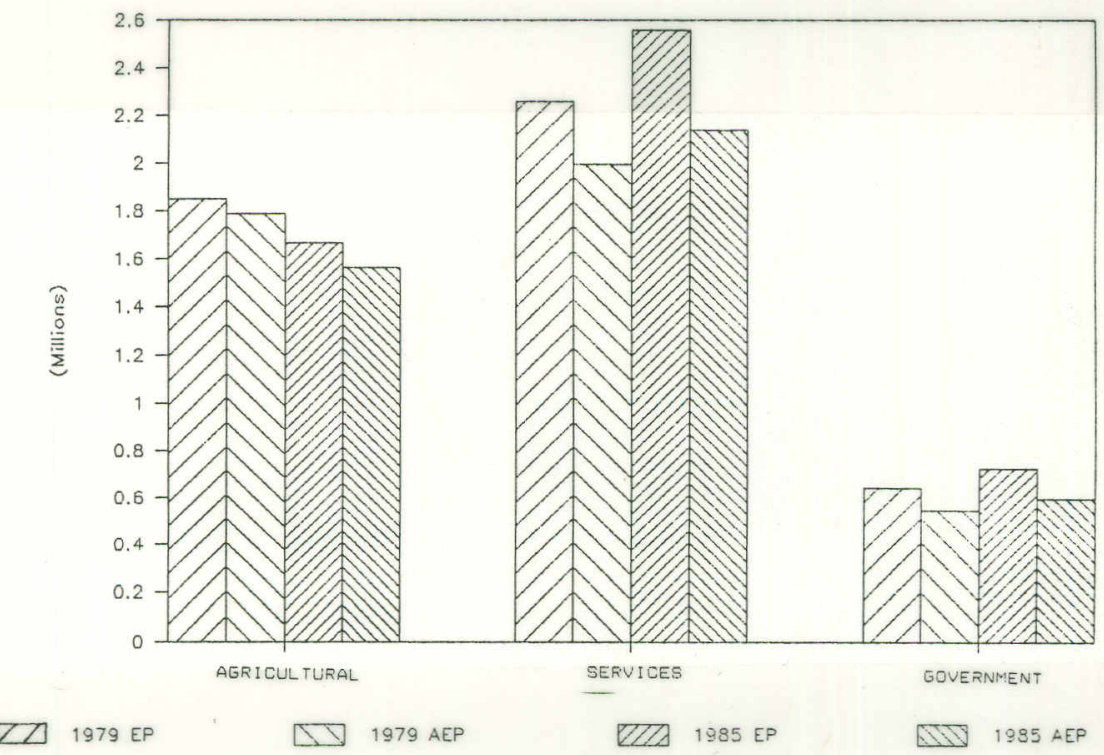

We assume that the adjustments for working hours of the number of employed persons with a certain educational background is fully determined by the occupation within a branch of industry they have. We therefore calculate the adjusted number of employed persons with certain educational backgrounds by multiplying those numbers with the average number of working hours of the occupation they have and industry they were working, so 2

$$
\operatorname{AEP}(b, 0, e, t):=\frac{\sum_{h} E P^{*}(b, o, h, t) * M H(h)}{\sum_{h} E P^{*}(b, o, h, t) * 40} * E P(b, o, e, t)
$$

with

$E P(b, o, e, t)$ : number of employed persons within industry $b$, occupation $o$, education $e$ at time $t$;

$\operatorname{AEP}(b, o, e, t)$ : adjusted number of employed persons within industry $b$, with occupation 0 and education e at time $t$.

2. For the estimation method we use in chapter 3 there is no difference between taking account of the employed people or the adjusted employed people when calculating the endogenous variable of the educational model. This is because of the fact that nominator and denominator are adjusted by the same factor. Only the estimated covariance matrix is touched by the adjustments made here for part-time work. 
The first term right of the equality symbol represents the average number of working hours of occupation 0 within industry $b$. The denominator of this term contains the normal working time of occupation o and industry $b$, which is here assumed to be 40 hours a week. By multiplying the first term by the number of persons employed in occupation 0 and industry $b$, which is the second term, the adjusted number of employed persons is found.

One conclusion of the study of Groot and Heijke mentioned above is that the shares of part-time work as measured by average working time per week are more determined by occupation than by industry. In figure III the employed persons and adjusted number of employed persons within the seven main occupations in 1979 and 1985 are compared. The correction for working hours is bigger in 1985 than in 1979 and seems to have the least impact on administrative, managerial workers and agricultural occupations (category 2 and 6 ). The relative small difference between adjusted and unadjusted numbers of employed persons in the agricultural industry is also found in figure IV; for the three main branches of industry the agricultural industry shows the least differences by the adjustments made.

Figure III. Employed persons and employed persons adjusted for the share of part-time work within seven occupational categories in 1979 and 1985

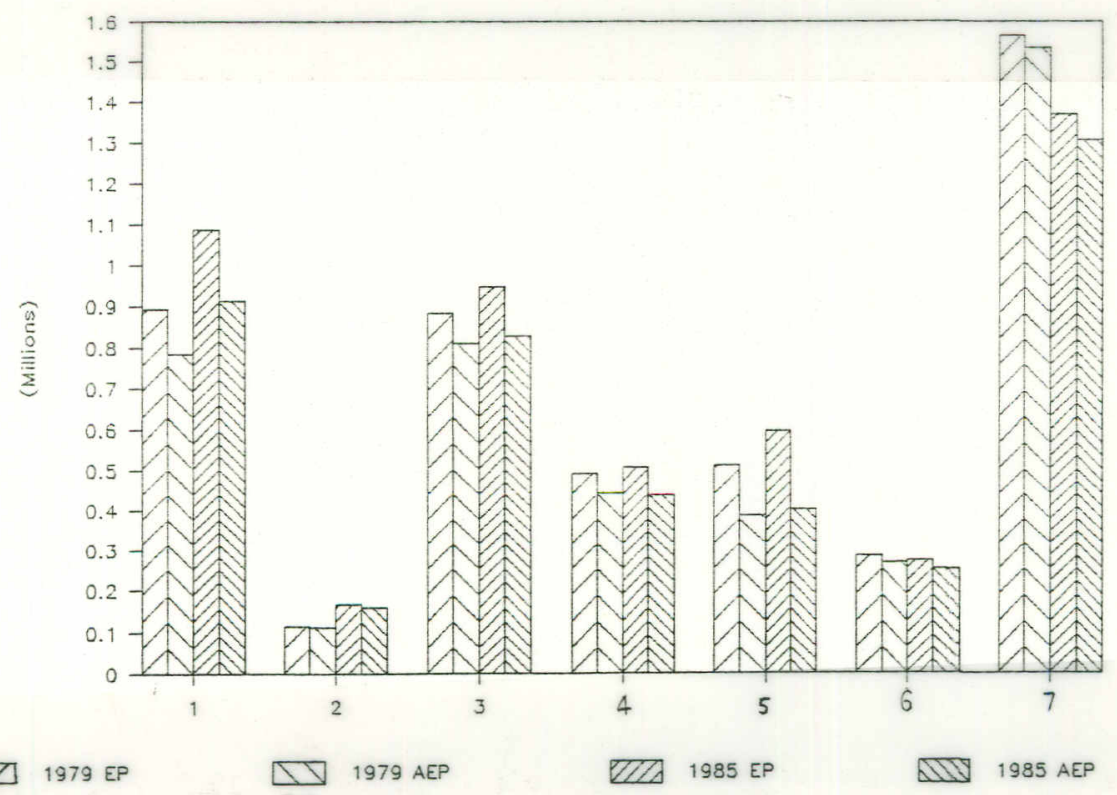

